\title{
Are interventions focused on gender-norms effective in preventing domestic violence against women in low and lower-middle income countries? A systematic review and meta-analysis
}

\author{
Agumasie Semahegn ${ }^{1,2^{*}}$ (D), Kwasi Torpey ${ }^{1}$, Abubakar Manu', Nega Assefa ${ }^{2}$, Gezahegn Tesfaye ${ }^{2}$ and
}

Augustine Ankomah ${ }^{1,3}$

\begin{abstract}
Background: One in three women experience intimate partner violence worldwide, according to many primary studies. However, systematic review and meta-analysis of intimate partner violence is very limited. Therefore, we set to summarize the findings of existing primary studies to generate evidence for informed decisions to tackle domestic violence against women in low and lower-middle income countries.

Methods: Studies were searched from main databases (Medline via PubMed, EMBASE, CINAHL, PopLine and Web of Science), Google scholar and other relevant sources using electronic and manual techniques. Published and unpublished studies written in English and conducted among women aged (15-49years) from 1994 to 2017 were eligible. Data were extracted independently by two authors, and recorded in Microsoft Excel sheet. Heterogeneity between included studies was assessed using $\mathrm{I}^{2}$, and publication bias was explored using visual inspection of funnel plot. Statistical analysis was carried out to determine the pooled prevalence using Comprehensive Meta-Analysis software. In addition, sub-group analysis was carried out by study-setting and types of intimate partner violence.

Results: Fifty two studies were included in the systematic review. Of these, 33 studies were included in the meta-analysis. The pooled prevalence of lifetime intimate partner violence was 55\% (95\% Cl: 52, 59\%). Of these, main categories were lifetime physical violence [39\% (95\% Cl: 33, 45\%); psychological violence [45\% (95\% Cl: 40, 52\%)] and sexual violence [20\% (95\% Cl: 17, 23\%)]. Furthermore, the pooled prevalence of current intimate partner violence was 38\% (95\% Cl: 34, 43\%). Of these, physical violence [25\% (95\% Cl: 21, 28\%)]; psychological violence [30\% (95\% Cl: 24, 36\%)] and sexual violence [7.0\% (95\% Cl: 6.6, 7.5\%)] were the pooled prevalence for the major types of intimate partner violence. In addition, concurrent intimate partner violence was 13\% (95\% Cl: 12, 15\%). Individual, relationship, community and societal level factors were associated with intimate partner violence. Traditional community gender-norm transformation, stakeholders' engagement, women's empowerment, intervention integration and policy/legal framework were highly recommended interventions to prevent intimate partner violence.
\end{abstract}

(Continued on next page)

\footnotetext{
* Correspondence: agucell@yahoo.com

'Department of Population, Family and Reproductive Health, School of

Public Health, College of Health Science, University of Ghana, Legon, Accra,

Ghana

${ }^{2}$ College of Health and Medical Sciences, Haramaya University, Po. Box 235,

Harar, Ethiopia

Full list of author information is available at the end of the article
}

(c) The Author(s). 2019 Open Access This article is distributed under the terms of the Creative Commons Attribution 4.0 International License (http://creativecommons.org/licenses/by/4.0/), which permits unrestricted use, distribution, and reproduction in any medium, provided you give appropriate credit to the original author(s) and the source, provide a link to the Creative Commons license, and indicate if changes were made. The Creative Commons Public Domain Dedication waiver (http://creativecommons.org/publicdomain/zero/1.0/) applies to the data made available in this article, unless otherwise stated. 
(Continued from previous page)

Conclusion: Lifetime and current intimate partner violence is common and unacceptably high. Therefore, concerned bodies will need to design and implement strategies to transform traditional gender norms, engage stakeholders, empower women and integrate service to prevent violence against women.

Protocol registration: PROSPERO: 2017: CRD42017079977.

Keywords: Domestic violence against women, Systematic review, Meta-analysis

\section{Plain English summary}

Domestic violence against women (VAW) is a well-recognized public health concern and systematic human rights violation. It has a serious negative impact on women's lives. Domestic VAW is common and still unacceptably high in different parts of the world as observed from several primary studies which have been conducted on the frequency and its associated factors. Additionally, some interventional studies have been conducted in some parts of the world revealed that gendernorms transformation through behavioral change and communication focused program can promote genderequality norm and avert domestic VAW. Summarized or synthesized evidence is still needed to inform and persuade policy makers and stakeholders, so they can take an evidence based decision making approach. One of the most challenging issue is that most countries' governments have considered VAW as a minor and socially tricky issue. There is some ambiguity as to whether VAW is a private or public matter. This systematic review and meta-analysis aimed at summarizing existing primary study findings to determine its level and associated factors, identify effective interventions to prevent domestic VAW and make key recommendations. The purpose is to contribute evidence to be used by program planners, policy makers, clinicians and other stakeholders to make an informed decision on the issue of domestic VAW. The study showed that more than half of the women experienced VAW, and almost one-third of the women have experienced current VAW. Intervention strategies should focus on traditional gender role transformation to minimize the relationship power-gap and prevent VAW.

\section{Background}

Globally, VAW is a well-recognized public health problem and a gross pervasive violation of human rights. About $35 \%$ of women experience VAW $[1,2]$, and almost two-third of women murders are committed by their intimate partners every year. About five percent of the women's total health years loss has been attributed by domestic VAW which is also exacerbated by authority inequity in relationship $[3,4]$. Additionally, VAW causes ill health and its associated devastating outcome are more than the cumulative problem of cancer, road traffic accidents and malaria which are massive threat and an uncontrollable public health challenge for the upcoming generation [4]. VAW is sturdily interconnected with gender inequality that affects women's negotiation ability about reproductive health and related issues [5-7]. The expenses associated with VAW has been estimated to be $3.7 \%$ of the countries' gross domestic product, which is almost comparable with what several countries devote on primary education [8]. Yet, it has been considered exclusively as private matter and negligible issue by the governments' of various countries, hence not perceived as a crime $[4,5,9]$.

Global and regional commitment to fighting domestic VAW is reflected in various international statues. For example, the United Nations aims to build an enabling household situation in improving women's right, their political participation, economic empowerment and safety [10]. In addition, provision of comprehensive and universal access to sexual and reproductive health care has been a strategy to avert domestic VAW in the Maputo Plan of Action (2016-2030) [11]. Further, research evidence has revealed that women empowerment and community mobilization are the most recommended interventions to minimize the expenses associated with VAW and its consequences [12]. The problem of domestic VAW is caused and exacerbated by poverty, alcohol consumption and societal receptive attitude towards inequitable gender-norms, which has been exhibited through denying access to education; lack of autonomy and justifying wife-beating by fellow women [9, 13-20].

Furthermore, women's experience of domestic violence is significantly associated with several and multiple poor physical and mental health outcomes $[1,9,14,17,21-$ 27]. Likewise, VAW has been associated with various poor reproductive health conditions such as HIV, unintended pregnancy and unsafe abortion $[1,4,7,9,15-18$, 20, 25, 28-41]. Therefore, VAW needs a comprehensive approaches to empower women economically, transform traditional gender-norms in improving their communication and negotiation skills [9, 17, 42]. There is a paucity of summarized evidence on; the level of domestic VAW, its associated factors, proven evidence on the 
technical approach and key research recommendations in low and lower-middle income countries (LLMICs). However, many primary studies have been conducted in LLMICs. The main purpose of this systematic review and meta-analysis was to summarize existing primary studies in LLMICs to determine the prevalence of domestic VAW and its associated factors; to identify effective and proven interventions and make key recommendations. It will provide an insight to policy makers, program planners, clinicians, researchers and other stakeholders to make an informed decisions on issues related to VAW.

\section{Review question(s)}

- What was the level of domestic VAW in LLMICs?

- What were the factors associated with domestic VAW in LLMICs?

- What were the research evidence that should translate into routine action in LLMICs?

- What were the studies' key recommendations on the prevention of domestic VAW in LLMICs?

\section{Method development and protocol registration}

The protocol for the systematic review and meta-analysis has been registered in the International Prospective Register of Systematic Reviews (PROSPERO) (ID: CRD42017079977). This systematic review and meta-analysis methods was written according to the preferred reporting items for systematic review and meta-analysis (PRISMA) guideline [43]. The filled PRISMA checklist is attached as Additional file 1.

\section{Searching methods and identifications of studies}

Studies were searched using medical subject headings (MeSHs), manual and email methods. Main electronic databases [Medline via PubMed, EMBASE, CINAHL, PopLine and Web of Science], direct Google search and other relevant sources were used to access studies before December 31st, 2017. In addition, emails were sent to authors whose studies were included to request studies. In addition, relevant citations from retrieved studies were searched. Search strings were constructed using keywords and their combinations based on the review questions. However, search strings were modified to suit to the databases interface accordingly. The overall detail of the search strategies are presented as Additional file 2: 2-1 to 2-4. The overall search results were exported to the Endnote citation manager software [44], and duplicate studies were removed.

\section{Eligibility criteria and type of studies included}

Observational and interventional studies were eligible to determine the level of, and factors associated with domestic VAW as well as effective interventions and key recommendations to prevent VAW. In addition, published and unpublished studies that have been conducted on women (15-49 years) in LLMICs to assess VAW and were written in English (1994-2017) were eligible for the systematic review. The LLMICs were selected based on the World Bank's country classification [45]. Case series, editorials, commentaries, life stories and fact sheet reports on VAW were excluded.

\section{Selection of studies}

Studies were selected using eligibility criteria and screened through four steps for the systematic review and metaanalysis. Initially, studies were screened and selected for subsequent evaluation based on their titles and abstracts, that is, if studies clearly reported on domestic VAW and its associated factors. Secondly, the two authors (AS and GT) independently screened the studies' abstract section (aims, methods, results and conclusion) to proceed to the next step. Studies whose abstract section briefly reported the prevalence of domestic VAW and its associated factors were included in the next evaluation process. Thirdly, studies selected by abstract screening were re-assessed independently by authors (AS and GT) with focus on the full-text. Eventually, selected studies were appraised for final inclusion in the systematic review and meta-analysis. In cases where the authors could not reach a consensus on studies, a third person was involved to appraise using same checklist, in the hope of helping to make a final decision. The studies selection process adhered to the PRISMA flow diagram [43] (Fig. 1).

\section{Measurement of outcomes and exposures}

The two phrases [domestic violence and intimate partner violence (IPV)] were interchangeably used as an outcome variable in this systematic review process. The outcome was assessed based on the prevalence of domestic/intimate partner VAW (psychological, physical, sexual and concurrent). IPV was presented in two forms (lifetime versus current). The lifetime IPV was assessed using the studies' report of women's experience of IPV during their lifetime. Furthermore, women's experience of IPV over the last 12 months preceding the survey was labeled as current IPV. Exposure variables were classified according to the ecological model (individual, relationship, community and societal level factors).

\section{Quality assurance of the systematic review}

Published and unpublished studies were searched for and considered for this systematic review to minimize publication bias. The electronic, manual and email search strategies were carried out to ensure comprehensive retrieval of studies from main databases and other relevant sources. Eligibility, quality assessment criteria, 


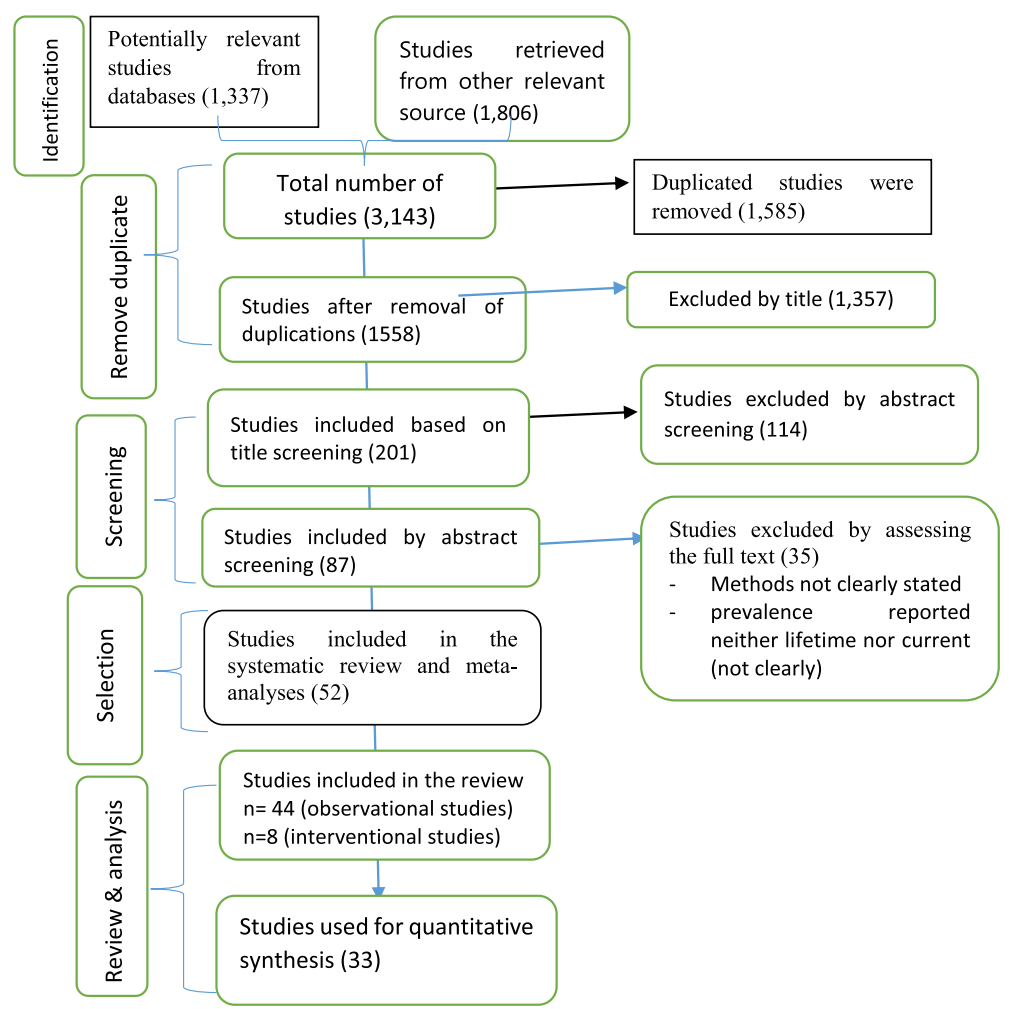

Fig. 1 Diagramatic presentation of the selection process of studies for systeamtic review

selection process and data extraction templates were properly designed by the authors to assure quality. Methodological quality assessment of the studies was carried out using the Joanna Briggs Institute (JBI) critical appraisal checklist for observational studies [46], for more detail of the critical appraisal is presented as Additional file 3. The authors (AS and GT) performed the selection of studies and data abstractions. Any disagreements were resolved through consensus, and sometimes, other authors who were not involved in data extraction adjudicated to make final decision. Potential publication biases were explored using the funnel plot. Detail of funnel plots for each outcome variables is included as Additional file 4: 4-1. Heterogeneity between included studies was assessed using $\mathrm{I}^{2}$. Sub-group analysis, random effects model and qualitative narration were carried out to minimize the risk of bias. In addition, the risk of bias (ROB) for interventional studies was assessed. The detail of the risk of bias assessment is attached as Additional file 4: 4-2.

\section{Study description and data extraction}

The studies' characteristics (authors-date, study area/ country), its aims, designs, sample size, sampling procedure, response rate, key findings and recommendations are described on a template. More details of the studies characteristics description are presented on tables [see Tables 1 and 2]. Two authors (AS and GT) abstracted the data from selected studies and labeled the data extraction template using Microsoft Excel sheet. Quantitative data, number of women who had experienced VAW (labeled $=$ Yes), who had not experienced VAW (labeled $=$ No) and total participants $(n)$ were separately recorded in a Microsoft Excel sheet. The more detail of abstracted data is stored in Excel Sheet (see Additional file 5).

\section{Data synthesis}

The pooled estimate of domestic VAW was computed using the Comprehensive Meta-Analysis (CMA) software [91]. Substantial heterogeneity was assumed to be $\mathrm{I}^{2}(>75 \%)$ [92, 93]. Potential publication bias was checked through visual assessment of the funnel plot $[94,95]$. The random effects model [96] was used to moderate the sample size variation which might have had an influence on the pooled estimate. In addition, sub-group meta-analysis was performed by study settings and types of domestic VAW (lifetime, current, psychological, physical and sexual violence). Furthermore, the associated factors with VAW were qualitatively synthesized according to the ecological framework 


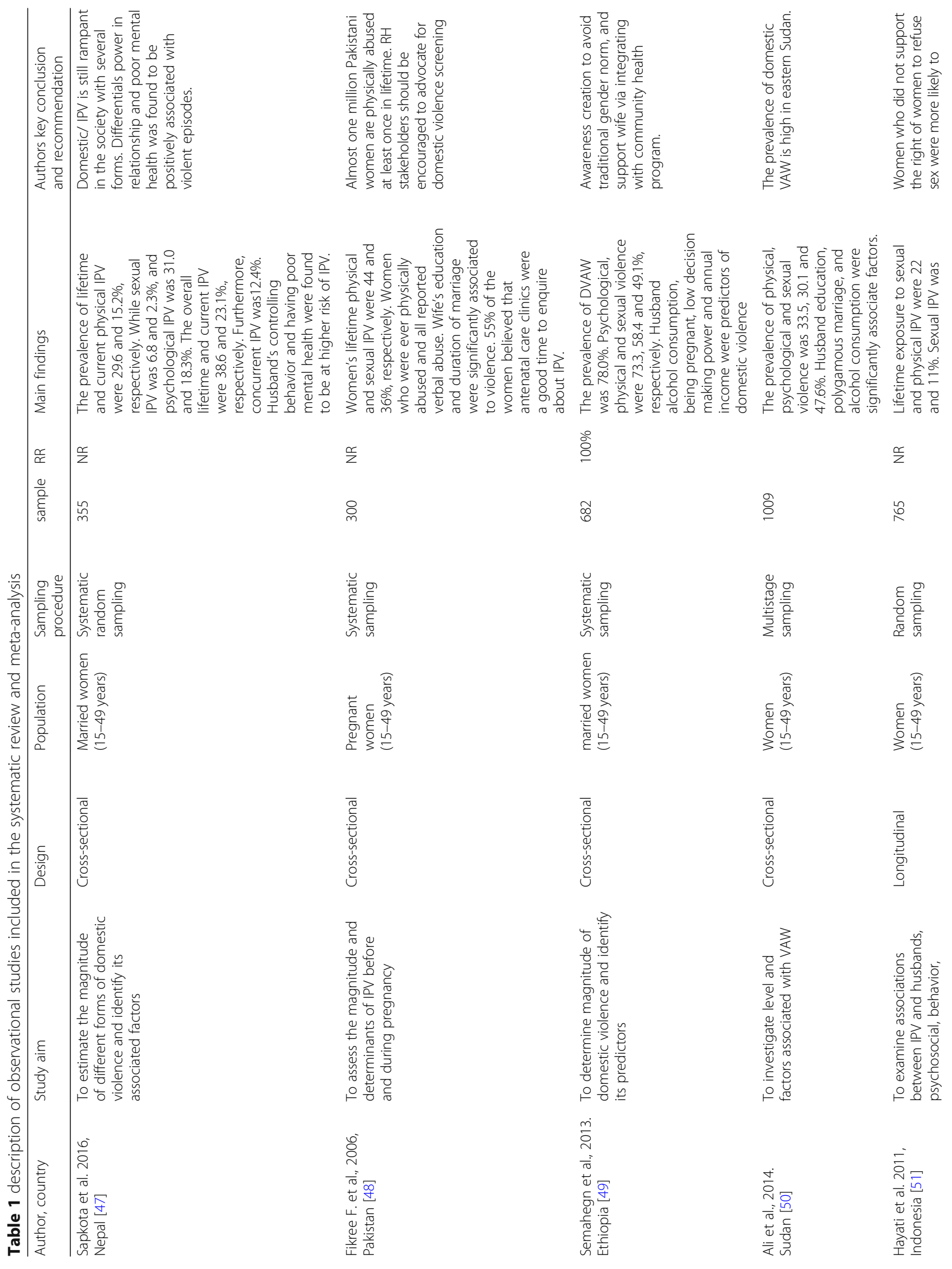




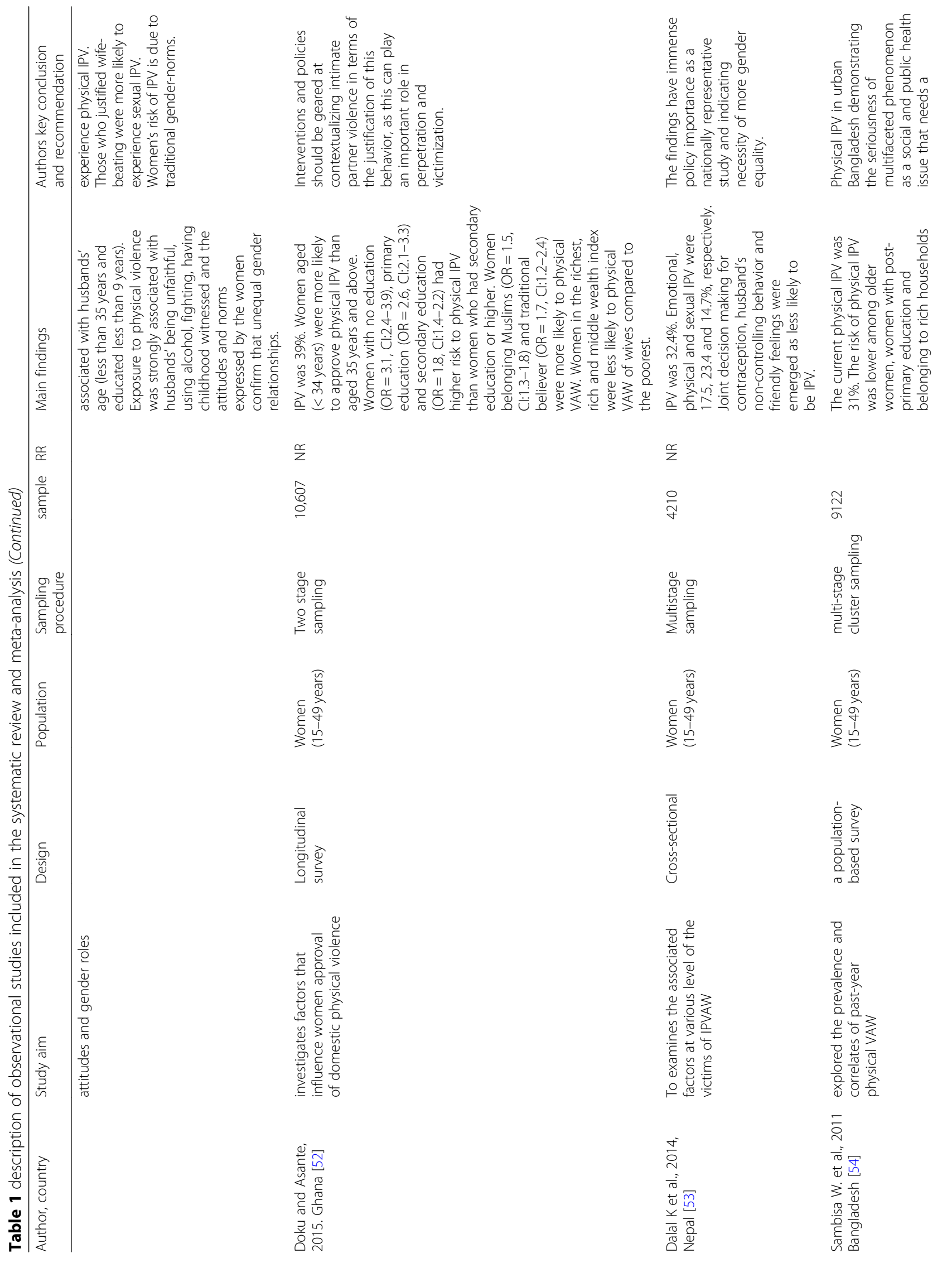




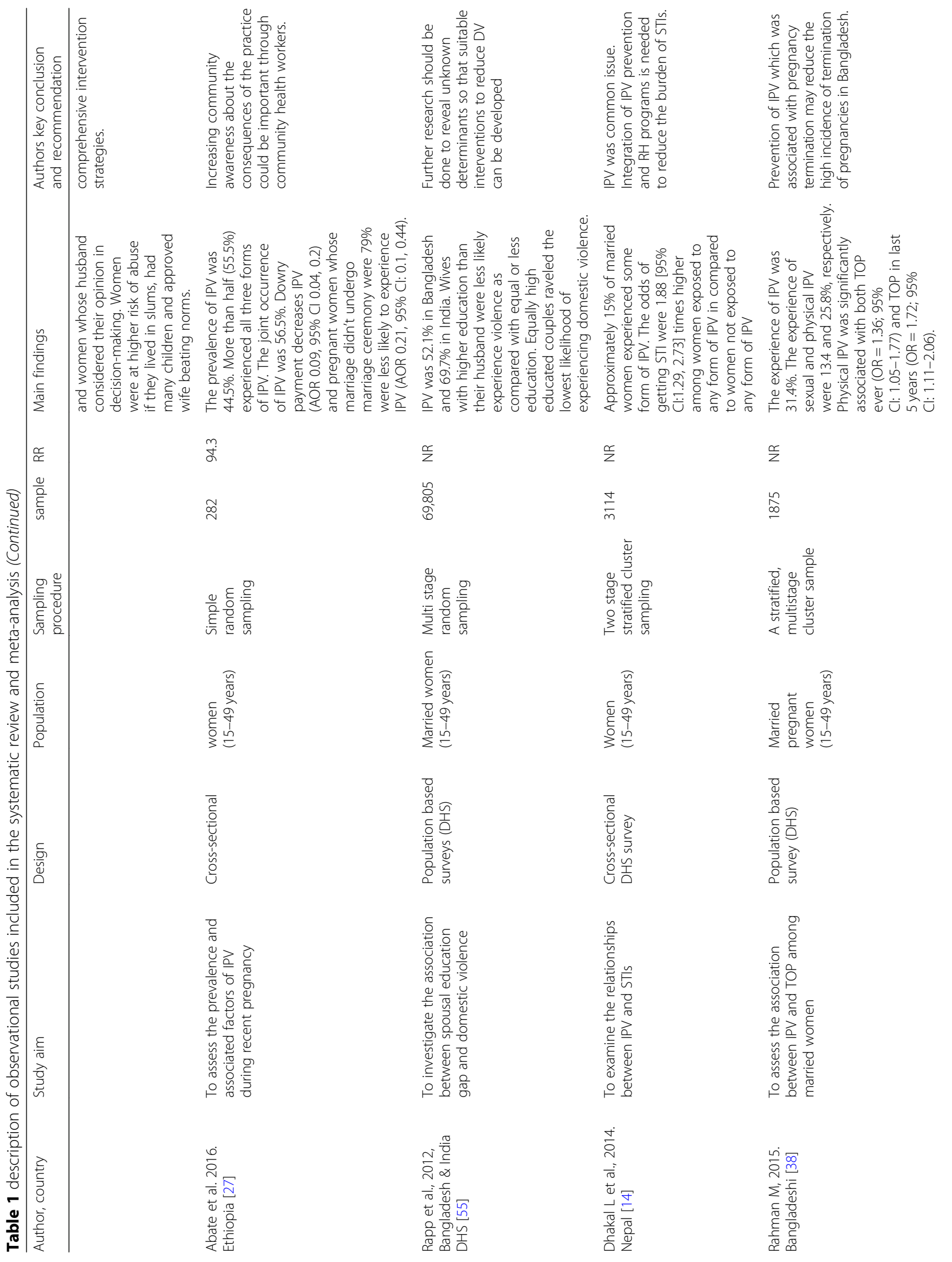




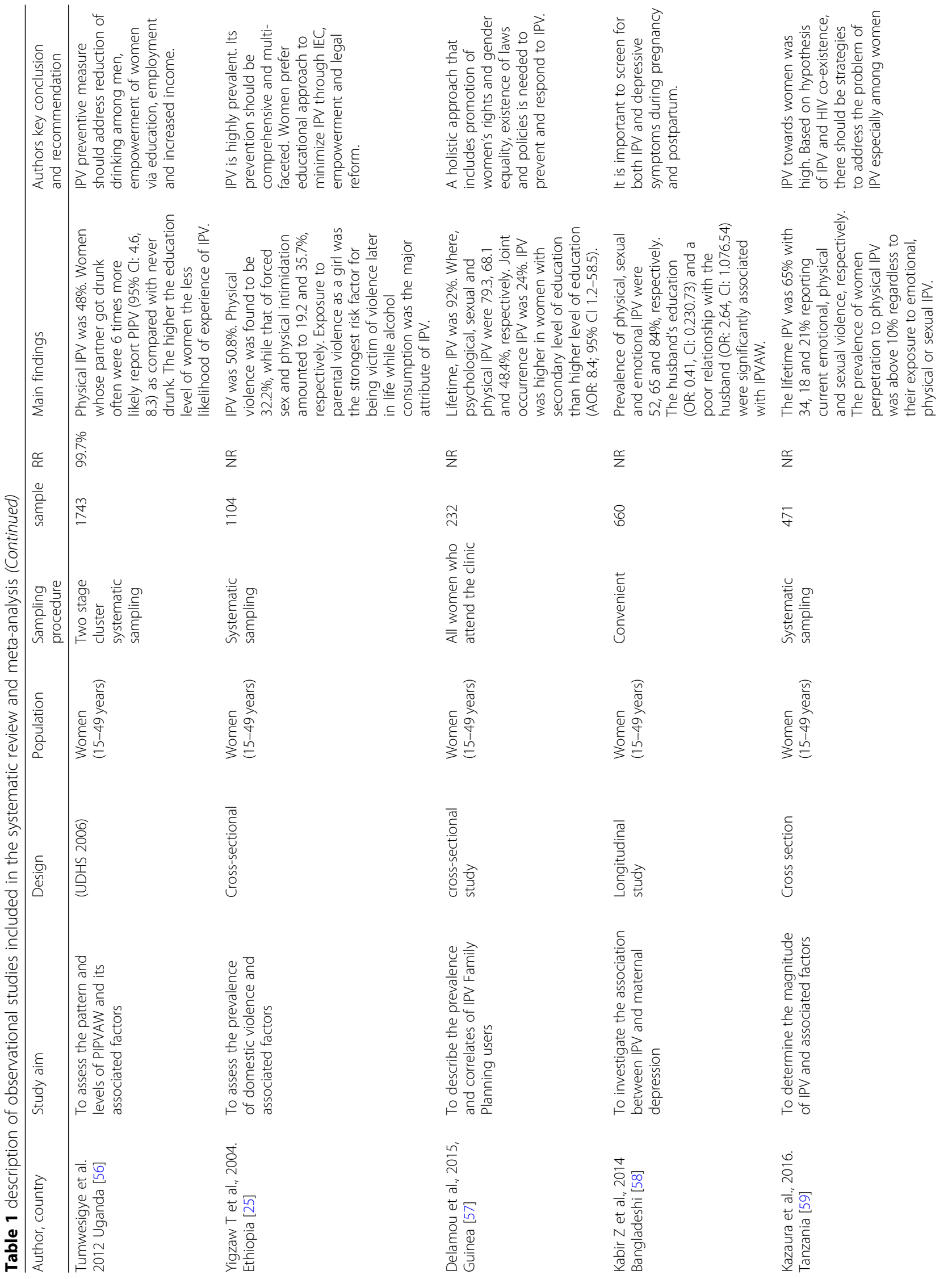


Semahegn et al. Reproductive Health

(2019) 16:93

Page 9 of 31

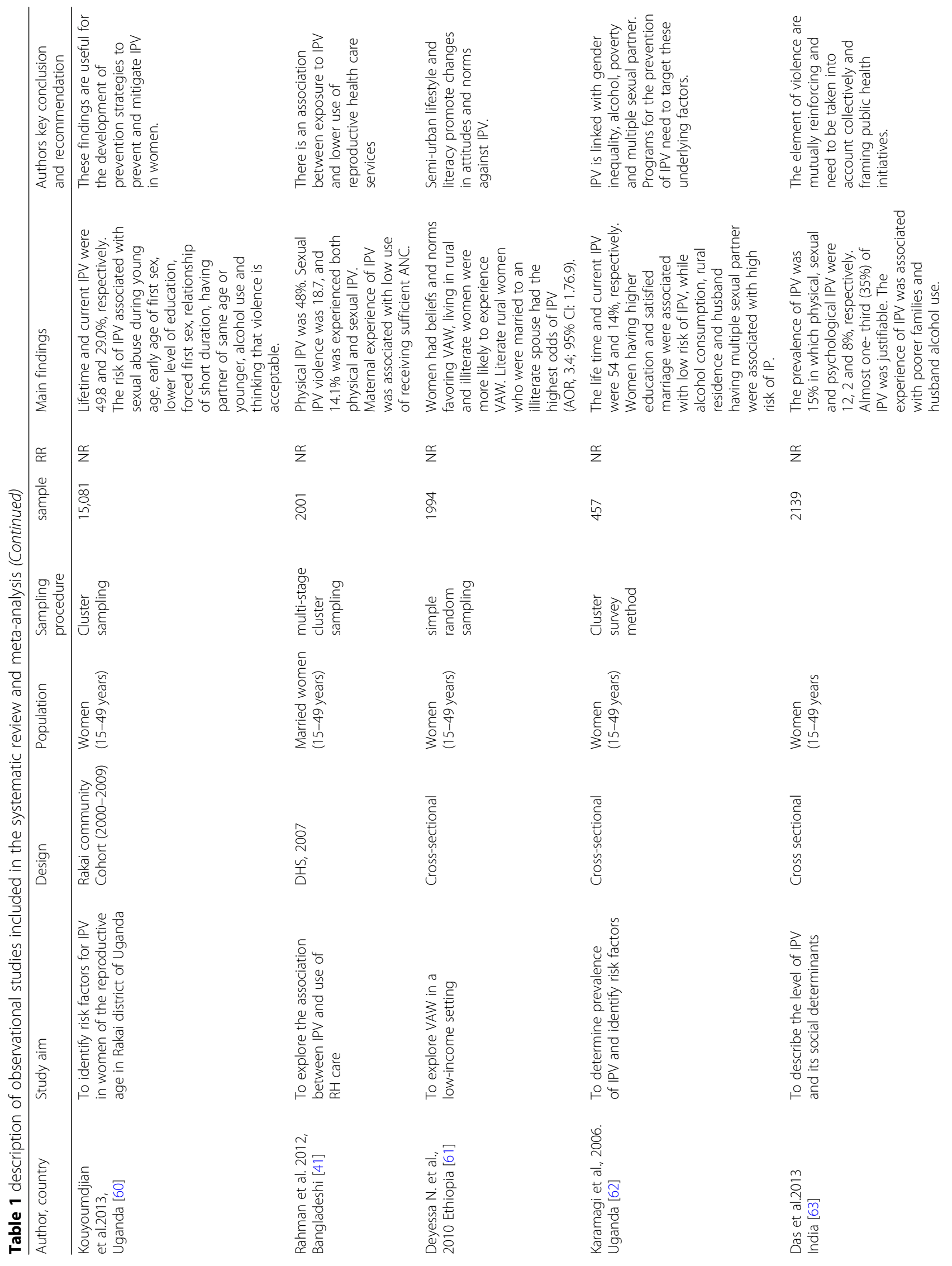


Semahegn et al. Reproductive Health

(2019) 16:93

Page 10 of 31

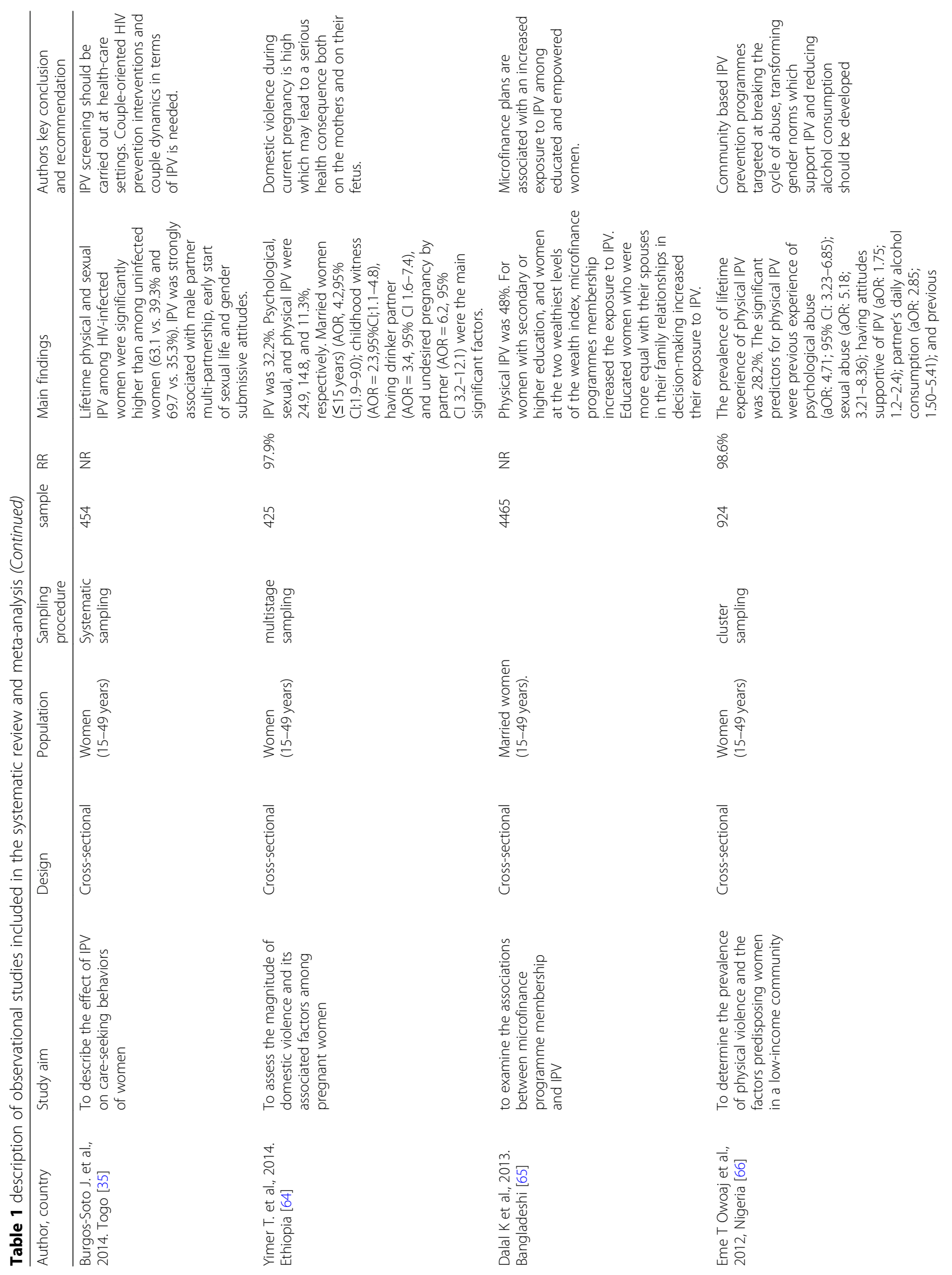




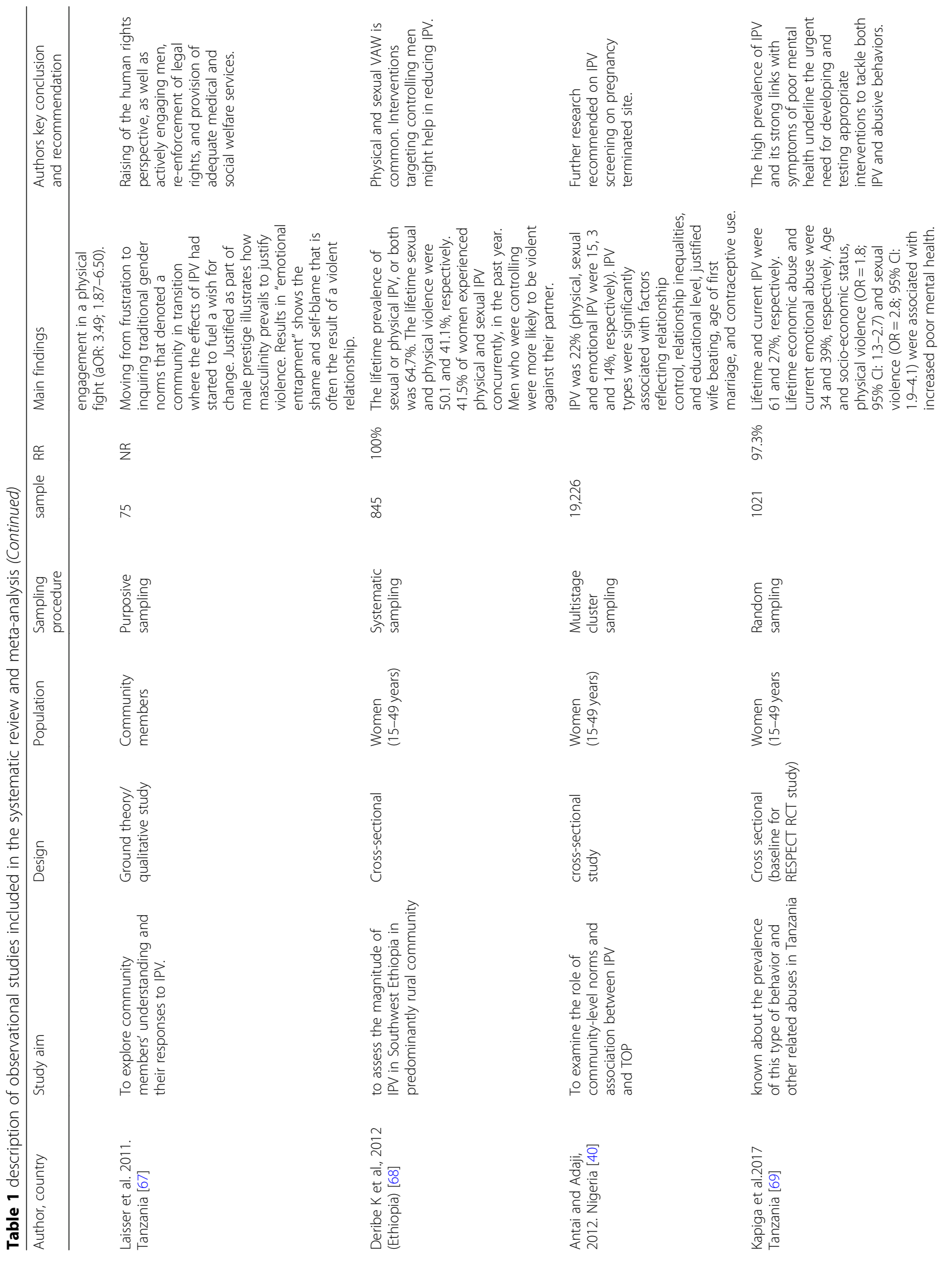



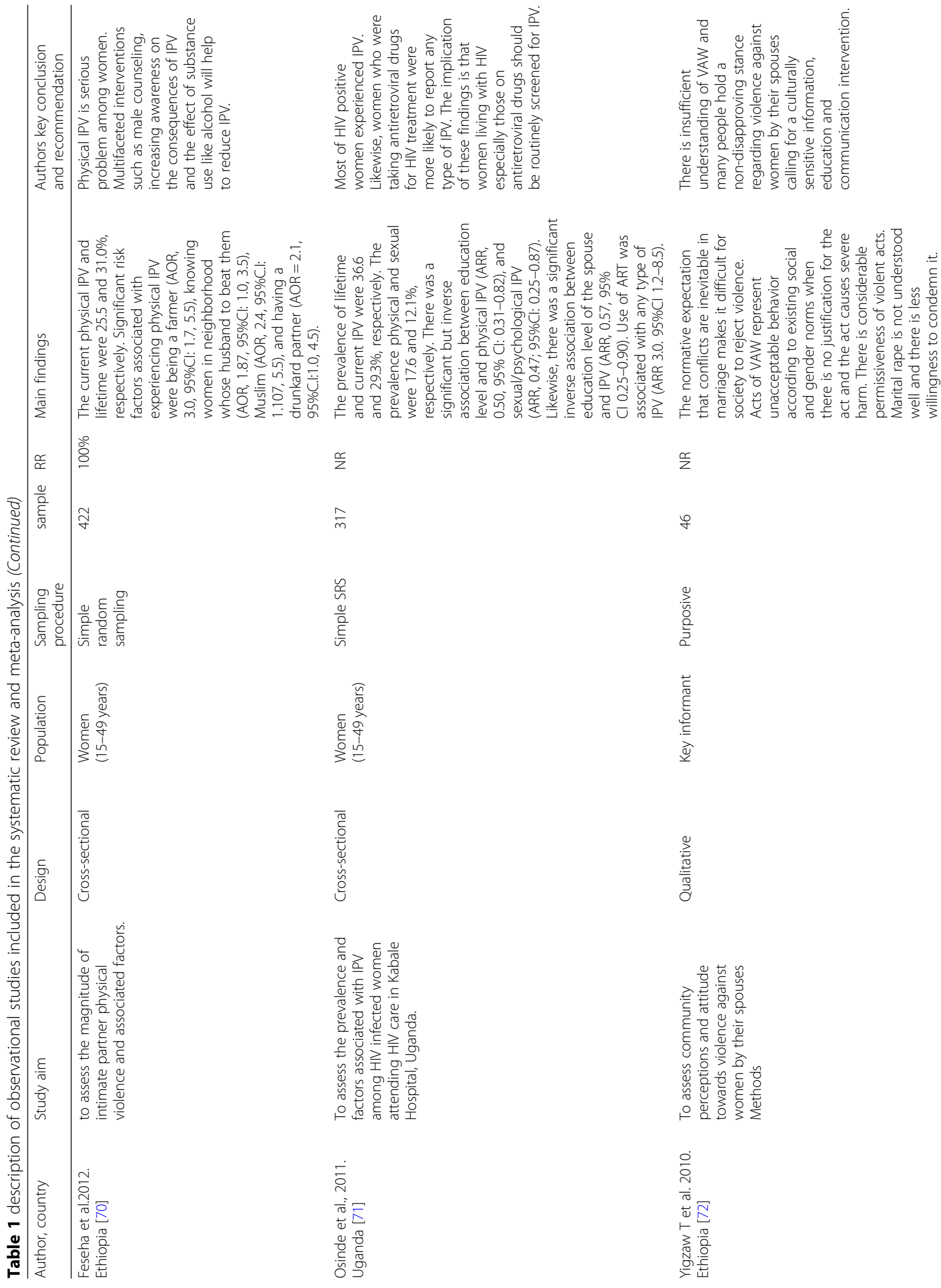

$\stackrel{\Re}{z}$

$\hat{m}$

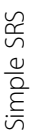

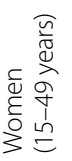

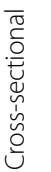

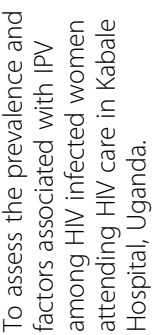

$\dot{\bar{\sigma}}$

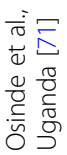

$\stackrel{⿳}{2}$

๖ำ

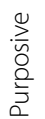

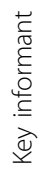

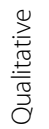

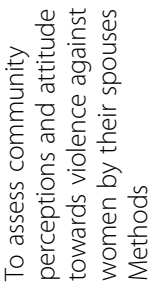

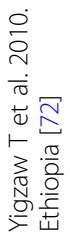


Semahegn et al. Reproductive Health

(2019) 16:93

Page 13 of 31

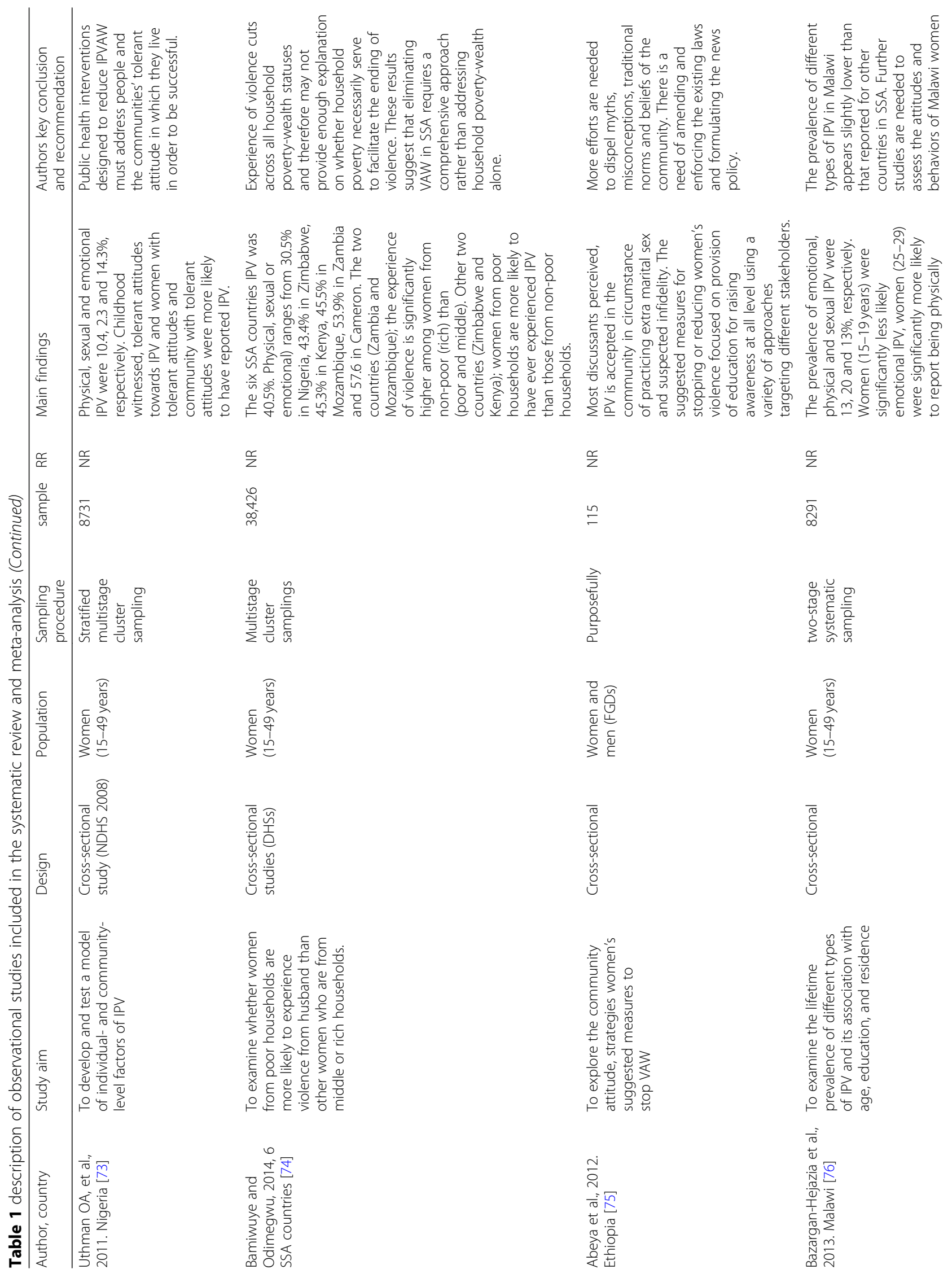


Semahegn et al. Reproductive Health

(2019) 16:93

Page 14 of 31

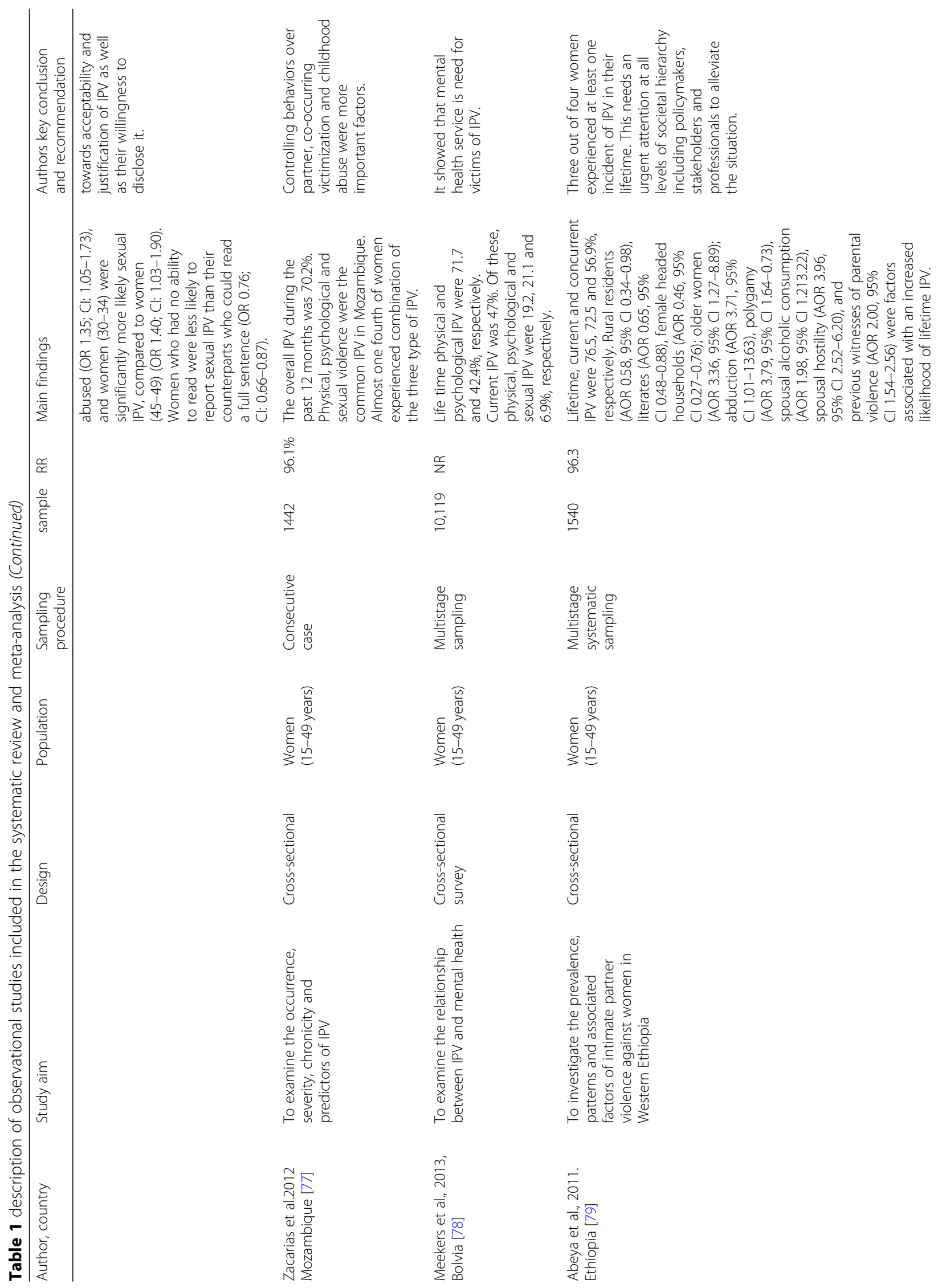


Semahegn et al. Reproductive Health

(2019) 16:93

Page 15 of 31

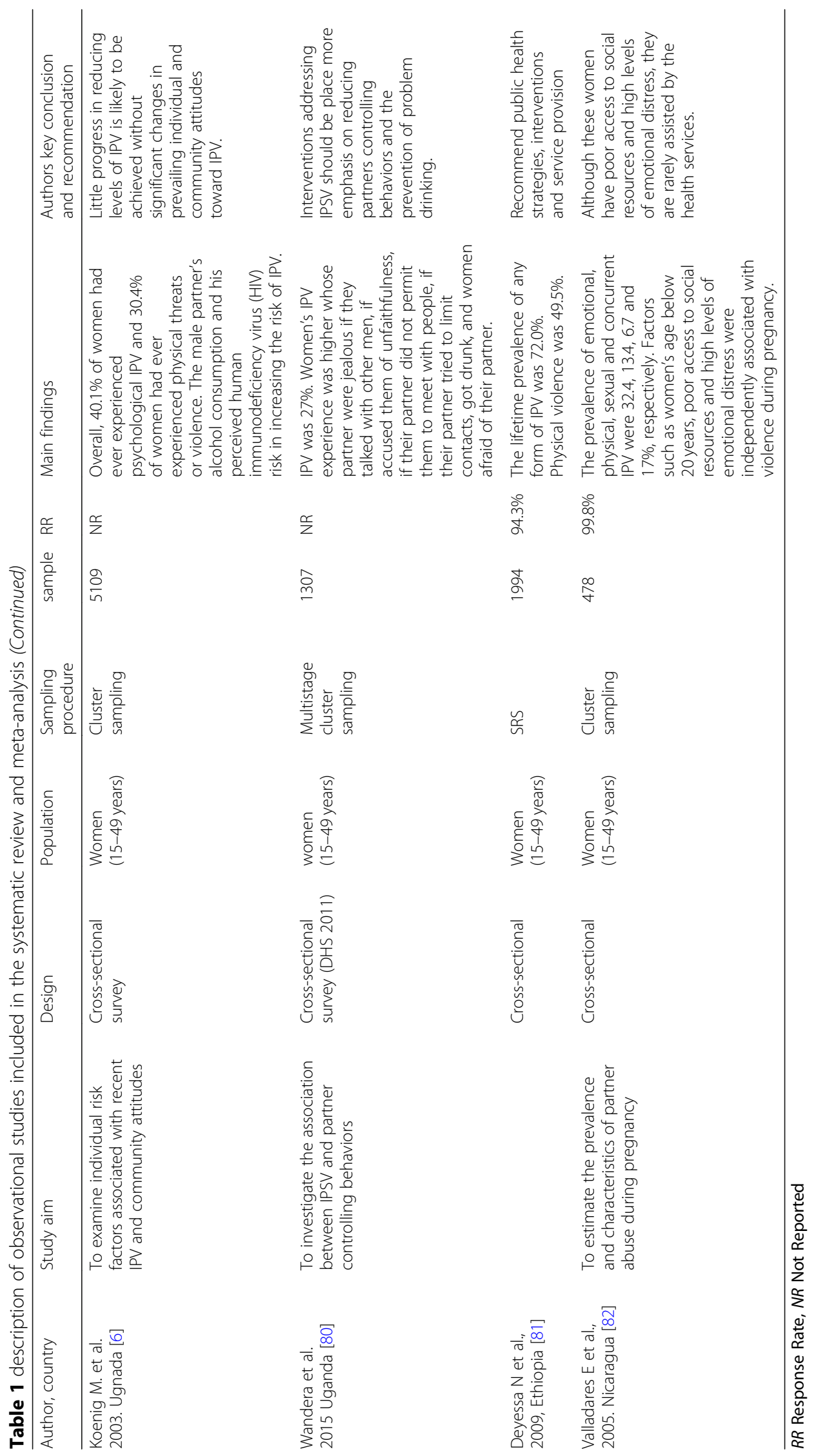




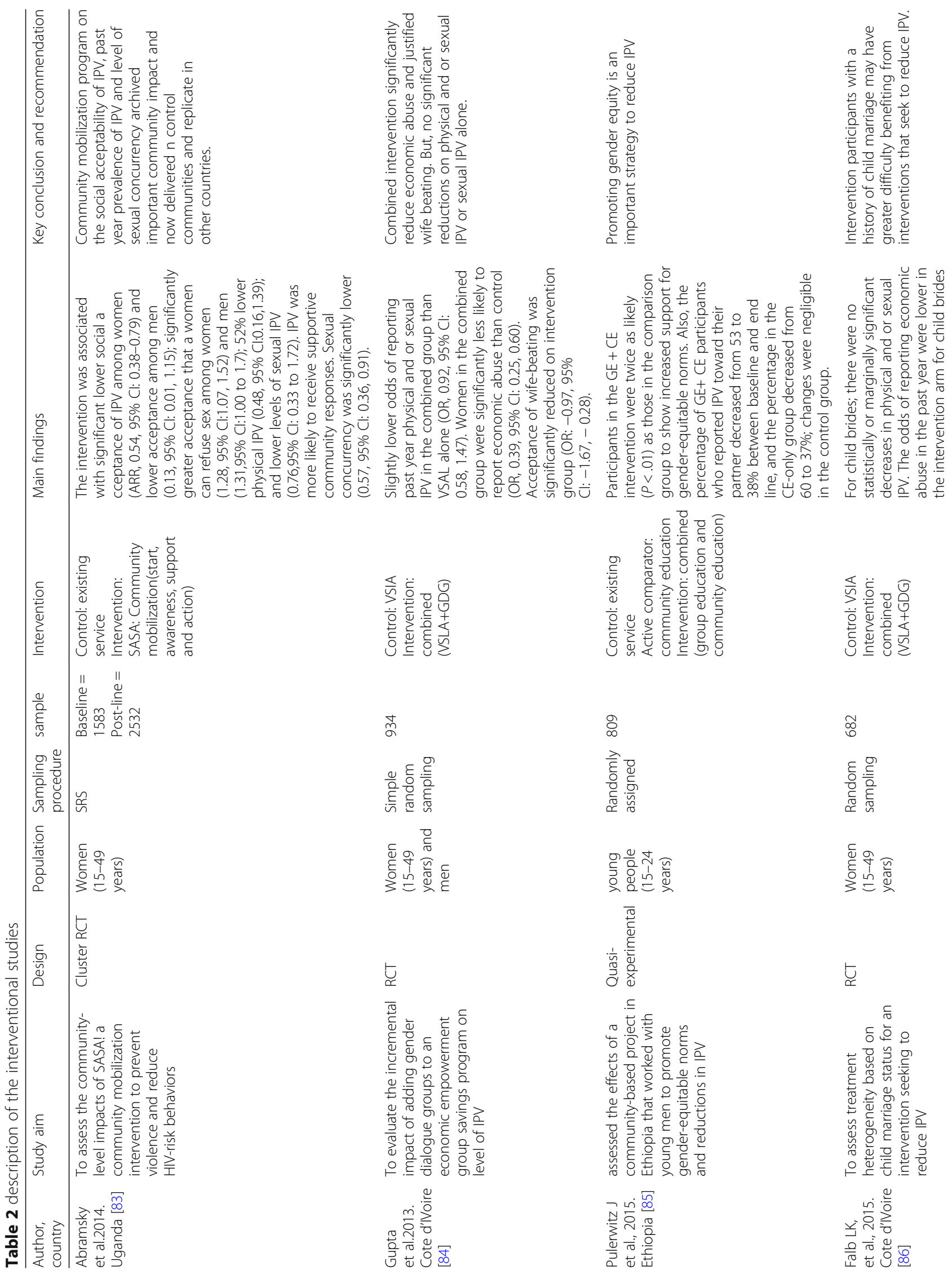




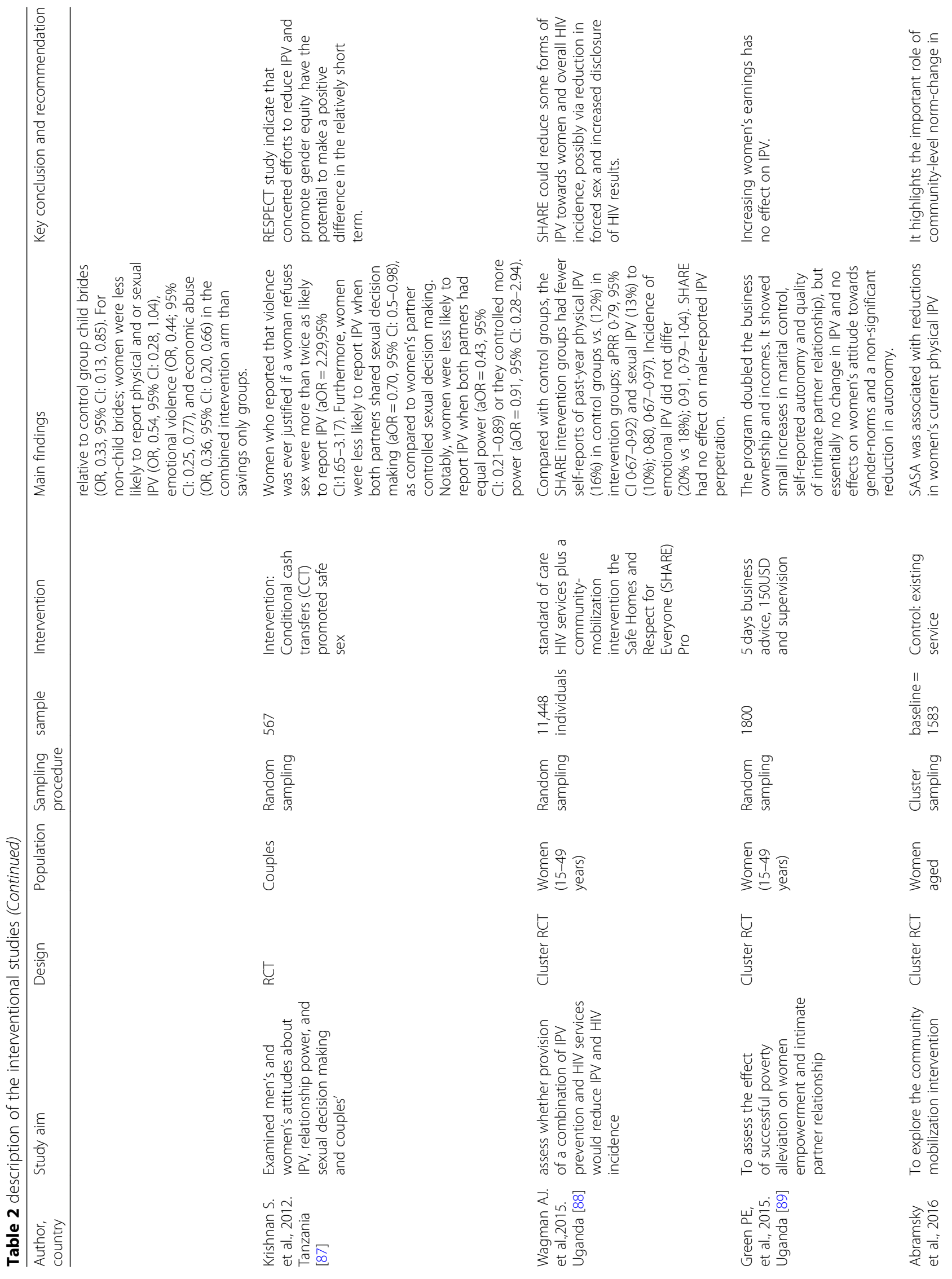




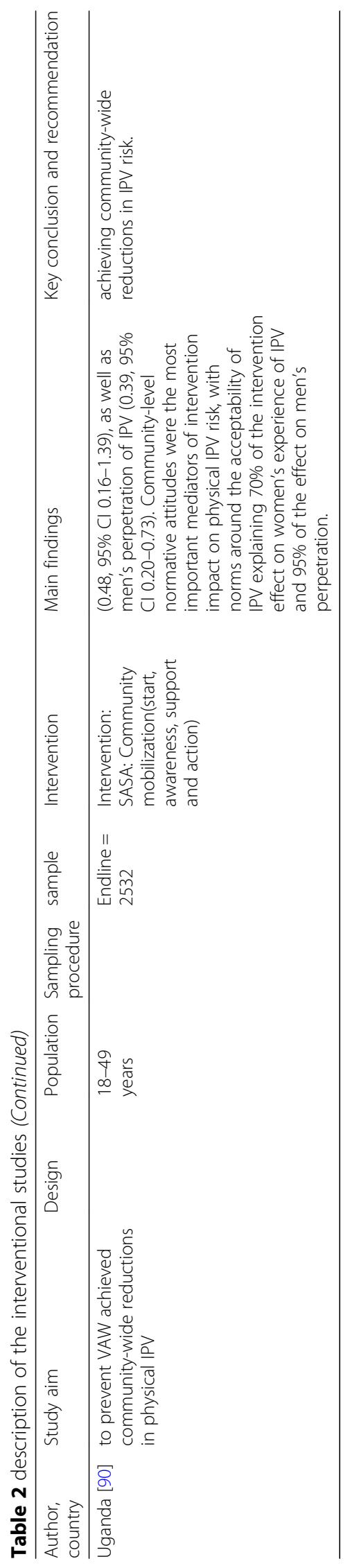




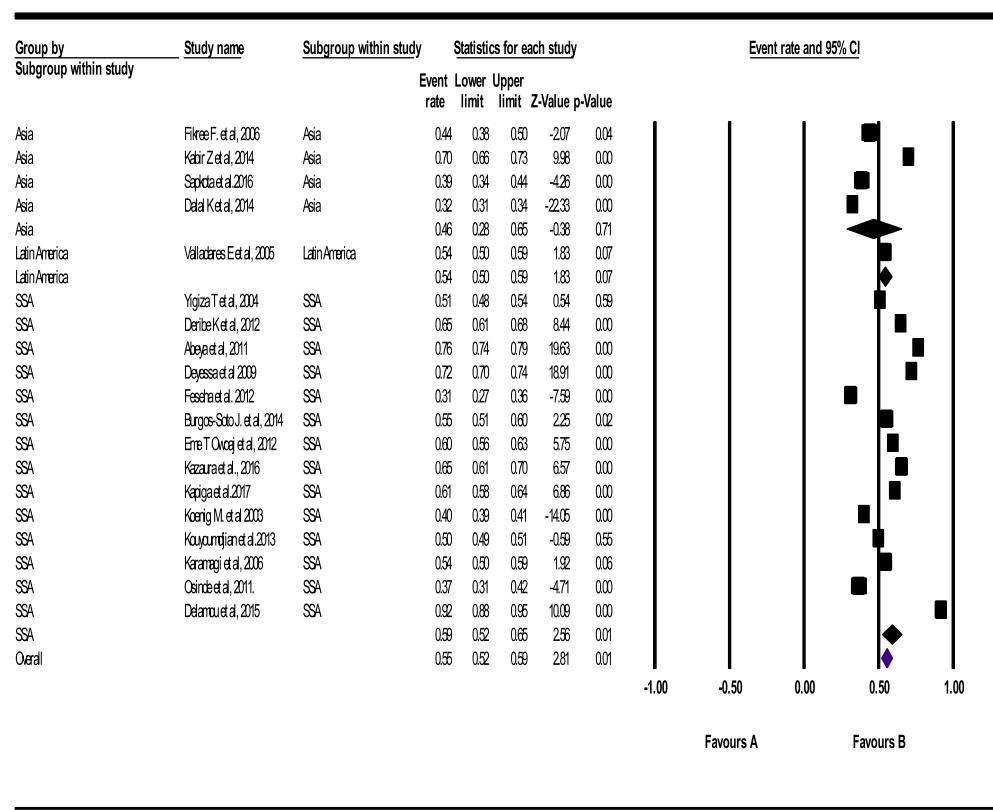

Meta Analysis

Heterogeneity: Tau $^{2}=0.30$, Standard Error $=0.19, d f=18(p<0.000) ; I^{2}=99.08 \%$

Test overall: $Z=2.806(p<0.005)$

Fig. 2 Forest plot of the lifetime intimate partner violence in LLMICs $(n=19)$

model (individual, relationship, community and societal factors) [97].

\section{Results}

Intimate partner violence in LLMICs

Lifetime intimate partner violence

Nineteen studies with a sample of 35,974 women (15-49 years), the pooled estimate of lifetime IPV was 55\% (95\% CI: 52, 59\%). IPV in sub-Saharan Africa (SSA) (14 studies) and Asian countries (4 studies) were 59\% (95\% CI: 52, 65\%) and 46\% (95\% CI: 28, 65\%), respectively (Fig. 2).

\section{Physical intimate partner violence}

From 18 studies with a sample of 44,664 women (15-49 years, the pooled prevalence of lifetime physical IPV was 39\% (95\% CI: 33, 45\%). Furthermore, lifetime IPV in SSA was 43\% (95\% CI: 35, 50\%) (Fig. 3).

\section{Psychological intimate partner violence}

From 15 studies with a sample of 42,600 women (15-49 years), the pooled prevalence of lifetime psychological IPV was $46 \%$ (95\% CI: 40, 52\%). The sub-group analysis shows consistent findings with the overall pool prevalence across the regions (Fig. 4).

\section{Sexual intimate partner violence}

From 15 studies with a sample of 29,127 women (15-49 years), the pooled prevalence of sexual IPV was $20 \%$ (95\% CI: 17, 23\%). The lifetime sexual IPV was the highest in SSA [42\% (95\% CI: 32, 54\%)] (Fig. 5).

\section{Current intimate partner violence}

Thirty three studies with a sample of 216,043 women (15-49 years), the pooled prevalence of IPV was $38 \%$ (95\% CI: 34, 43\%). The prevalence in SSA is almost similar with the pooled prevalence (Fig. 6).

\section{Types of current intimate partner violence Physical intimate partner violence}

From thirty one studies with a sample of 141,820 women (15-49 years), the pooled prevalence of physical IPV during the past 12 months was 25\% (95\% CI: 21, 28\%). The subgroup analysis of seven studies in Asian countries was 31\% (95\% CI: 22, 41\%) (Fig. 7).

\section{Psychological intimate partner violence}

From 20 studies with a sample of 115,798 women (15-49 years), the pooled prevalence of psychological IPV was 30\% (95\% CI: 24.0, 36\%) (Fig. 8). 


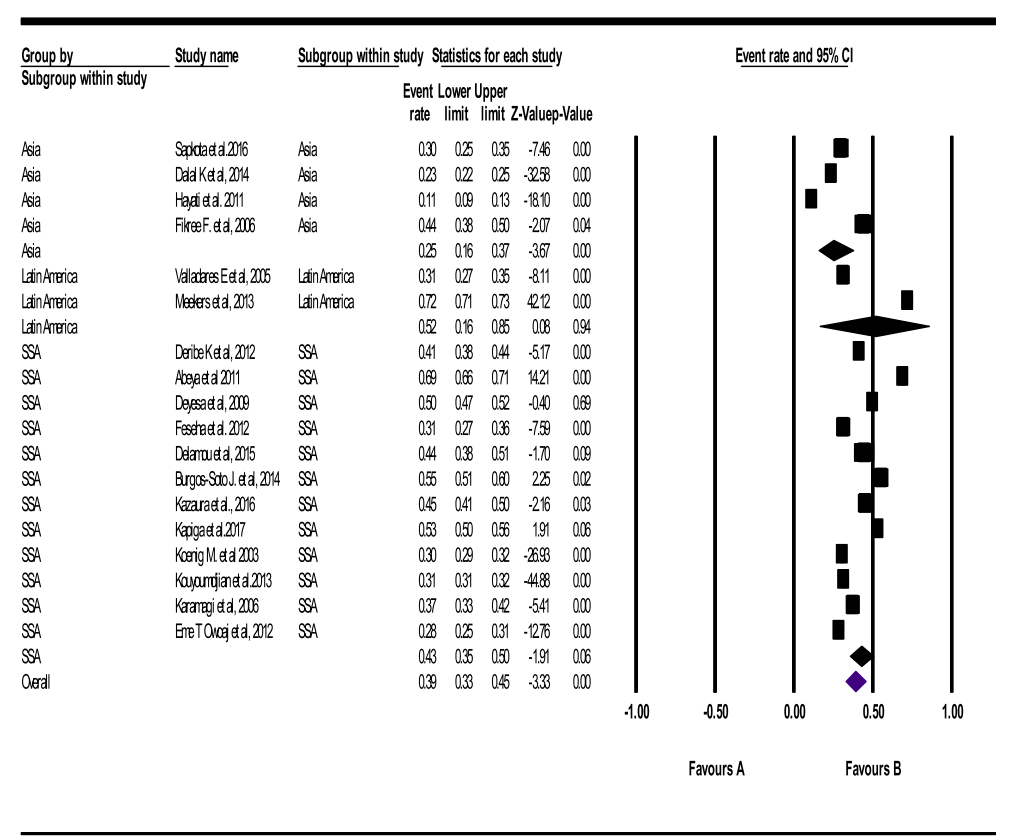

Meta Analysis

Heterogeneity: Tau $^{2}=0.744$, Standard Error $=0.456, d f=17(p<0.000) ; I^{2}=99.7 \%$

Test overall: $Z=-3.333(p<0.001)$

Fig. 3 Forest plot of the Lifetime physical intimate partner violence against women $(n=18)$

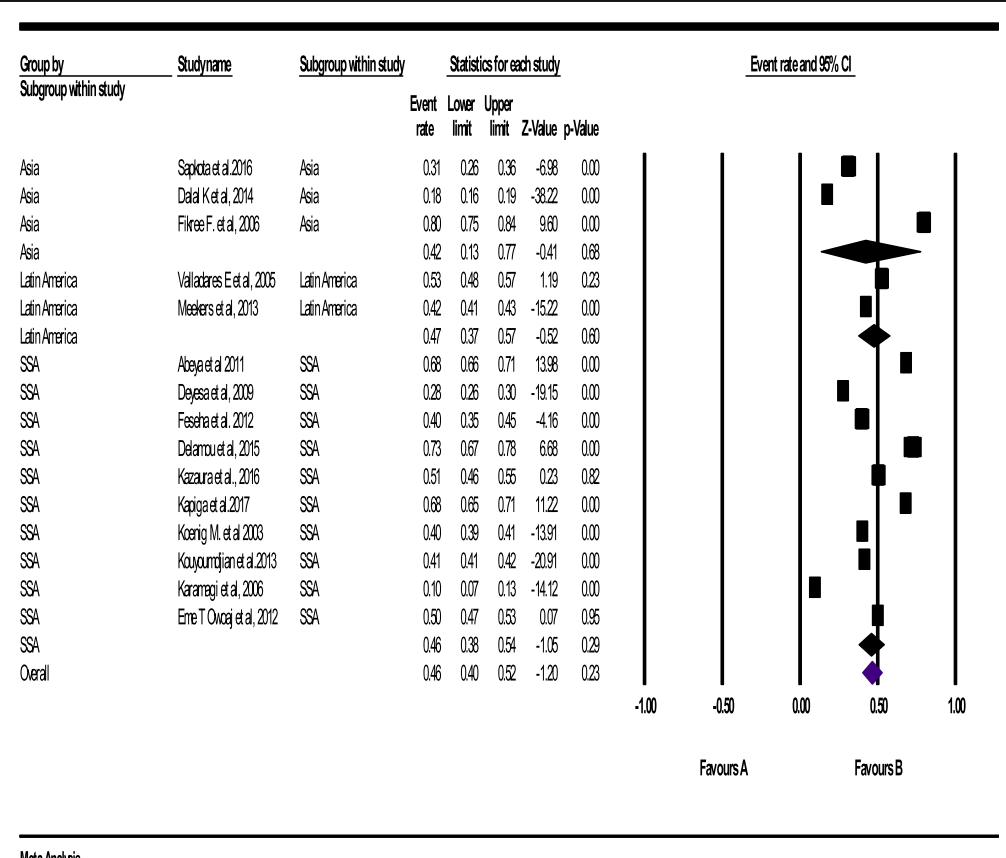

Meta Anajsis

Heterogeneity: Tau $^{2}=0.290$, Standard Error $=0.201, d f=14(p<0.000) ; I^{2}=99.46 \%$

Test overall: $Z=-1.423(p<0.000)$

Fig. 4 Forest plot of the lifetime psychological intimate partner violence against women $(n=15)$ 


\begin{tabular}{|c|c|c|}
\hline Goupby & Studyname & Subgrap vititin stuc \\
\hline \multicolumn{3}{|l|}{ Subgroup witin study } \\
\hline Asia & Sapkota eta.2016 & Asia \\
\hline Asia & Dalal Kelal, 2014 & Asia \\
\hline Asia & Hayad eta. 2011 & Asia \\
\hline Asia & Filkee F.etal, 2006 & Asia \\
\hline \multicolumn{3}{|l|}{ Asia } \\
\hline LainAmeica & Valladaes Eeta, 2005 & Latin America \\
\hline \multicolumn{3}{|l|}{ LainAmerica } \\
\hline SSA & Deibe Ketal, 2012 & SSA \\
\hline SSA & Abeja eta 2011 & SSA \\
\hline SSA & Deyesa ela, 2009 & $S S A$ \\
\hline SSA & Delamou etal, 2015 & SSA \\
\hline SSA & Burgossolio J.eta, 2014 & LSSA \\
\hline SSA & Karuua etal., 2016 & SSA \\
\hline SSA & Kapiga etala.2017 & SSA \\
\hline SSA & Koysoungian etal.2013 & $S S A$ \\
\hline SSA & Karamagi etal, 2006 & SSA \\
\hline SSA & Eme T Onoaj etal, 2012 & $S S A$ \\
\hline \multicolumn{3}{|l|}{ SSA } \\
\hline Oeral & & \\
\hline
\end{tabular}

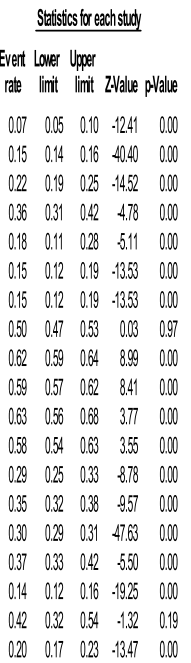

Everifrate and $95 \%$ C C
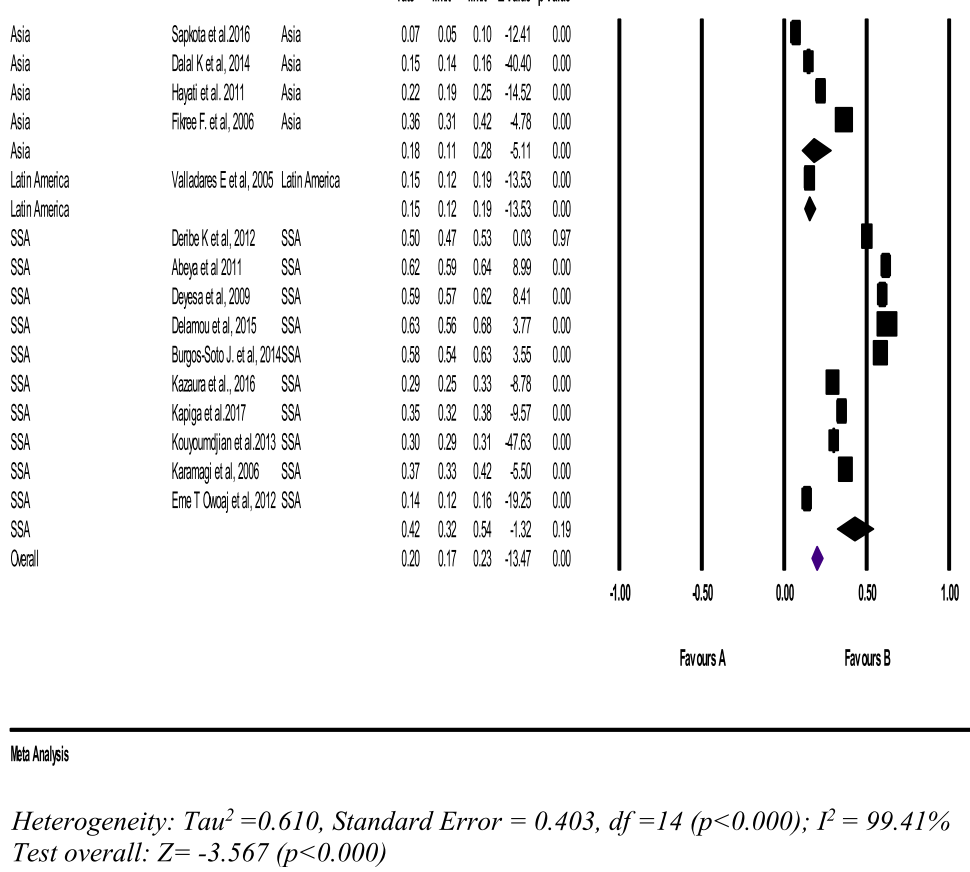

Fig. 5 Forest plot of the lifetime sexual intimate partner violence against women $(n=15)$

\section{Sexual intimate partner violence}

From 27 studies with a sample of 124,739 women (15-49 years), the pooled prevalence of current sexual IPV was $7 \%$ (95\% CI: 7, 8\%). However, the subgroup pooled prevalence was a bit higher than the overall pooled prevalence. It was 19\% (95\% CI: 13, 27\%) in SSA countries (Fig. 9).

\section{Concurrent intimate partner violence}

From eleven studies with a sample of 8315 women (15-49 years), the pooled prevalence of women's experience of IPV concurrently was $13 \%$ (95\% CI: $12,15 \%)$. In the meantime, the prevalence of concurrent IPV in SSA was $27 \%$ (95\% CI: 16, 42\%) which is two times higher than the overall pooled IPV prevalence in LLMICs (Fig. 10).

\section{Contributing factors of domestic violence against women Individual level factors}

Socio-demographic factors The socio-demographic characteristics of the couples were identified as factors associated with IPV. In six studies, place of residence was one of the factor associated with IPV whereby women living in rural area were more likely to experience IPV than urban dwellers [25, 52, 61, 62, 65, 79]. Similarly, in two studies, women's religion was a factor associated with IPV, such that women belonging to Islam were more likely to experience IPV than non-
Muslim [65, 70]. In addition to Muslim women, women belonging to the traditional religion (worshipers) and being in other faith(s) were more likely to accept physical IPV than women belonging to Christianity [52].

Age Differences between women's and their husbands' age had an inconsistent relationship with the experience of IPV. In three studies, physical IPV was significantly associated with women's age and age at first marriage $[40,48,56]$. Women's age 20 years and younger was a risk factor associated with IPV [82]. In one study, women who married at age 15 or young were four times more likely to experience IPV than women got married older than 15 years [64]. While women (15-19 years) were less likely to report emotional IPV, women (25-29 years) and women (30-34 years) were more likely to report being physical and sexual IPV, respectively than women (45-49 years) [76]. Nevertheless, in two studies, older age women (35-49years) were three times more likely to report lifetime and current IPV than women (15-19 years) [53, 79]. In addition, the age of husbands was a positive predictor of IPV [40, 49], but sexual IPV was associated with husbands younger than 35 years [51].

Education Women's lifetime IPV remained significantly associated with women's level of education. In six studies, uneducated or primary educated women had almost 


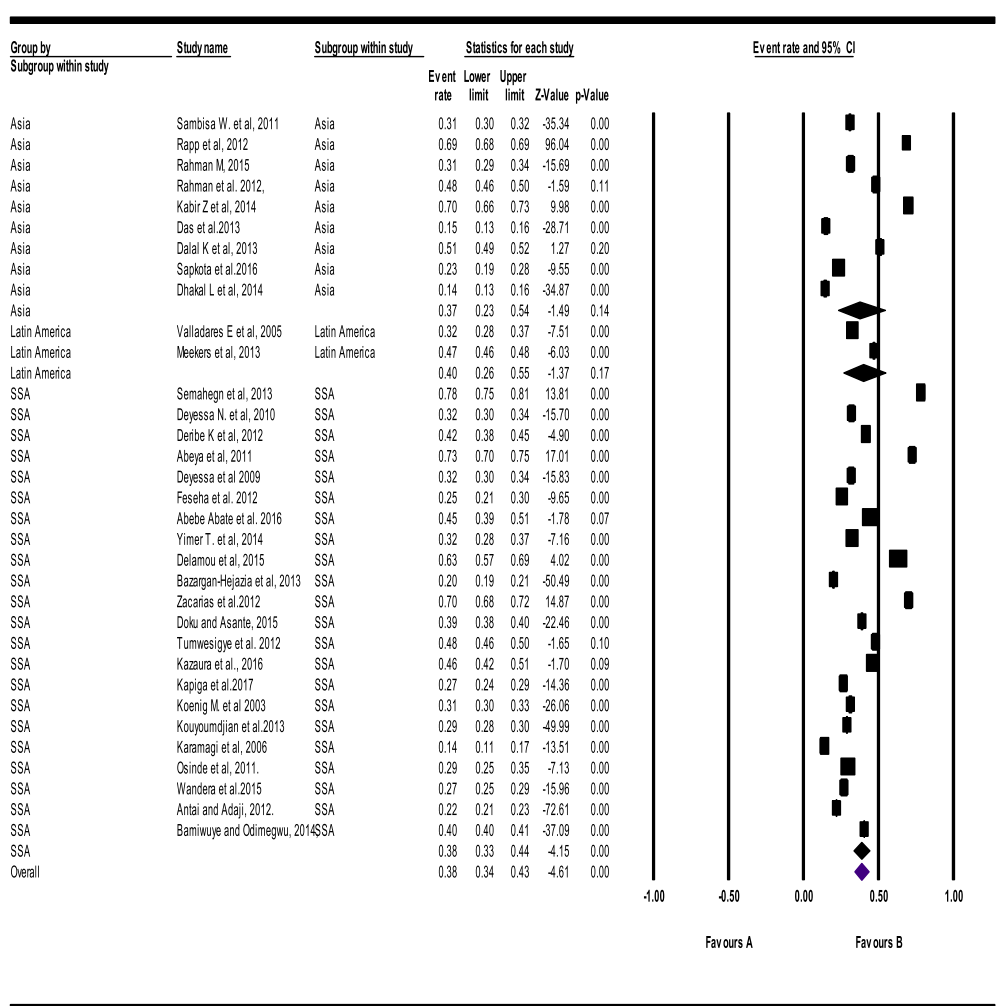

Meta Analysis

Heterogeneity: Ta $^{2}=0.698$, Standard Error $=0.385, D f=32(p<0.000) ; I^{2}=99.88 \%$

Test overall: $Z=-3.302(p<0.001)$

Fig. 6 Forest plot of the current intimate partner violence against women $(n=33)$

double the prevalence rate of any form of IPV who attended secondary or higher education $[6,48,52,53$, $60,65]$. In five studies, the higher the women's educational level, the lesser the likelihood of experiencing physical IPV. Women with higher education than their husbands were less likely to experience IPV than women with equal or less education than their husbands [40, 55, $56,62,71]$. In two studies, women in equally high educated marriages revealed the lowest likelihood of experiencing IPV. Education was found to be significantly protective from IPV, for both women as victim and men as perpetrator [55, 79]. Furthermore, the educational status of husbands was associated with women's experience of less IPV and less violent behavior to their wives $[27,50,53,54$, 58]. On the other hand, women with no education were about three times more likely to approve (accept) IPV than women with secondary or higher education [52]. IPV remained higher and even increased in the case of women with secondary to vocational levels of education as compared to those with a higher level of education $[57,66]$.

Occupation In two studies, women who were engaged in manual labor (farming) were three times more likely to be exposed to IPV than women with non-farming occupations $[66,70]$. In one study, women who has been in the poorest microfinance group under supported by the microfinance programmes in Bangladesh have no significant change on IPV exposure, except some improvement on economic empowerment [65]. Likewise, the women whose partners are employed (earned in cash) were 93\% less likely to experience physical IPV than those women whose partners were farmers (earned in kind) [70]. Likewise, in three studies, women were economically dependent, and or did not have their own means of earnings and controlling their earnings were more likely to report sexual IPV than their counterparts [49, 51, 72]. Similarly, women heading business or engaged in different types of jobs were $50 \%$ less likely to report lifetime IPV than women have not heading business (almost jobless women) [79]. On the contrary, housewives were less likely to be experienced sexual IPV than women who have a job different from housewives [68].

Childhood witness Domestic IPV was significantly associated with women and their husband childhood wittiness of parental violence. Although the strength of association varies (ranged from four to thirteen times), those women whose mothers were hit by their fathers 


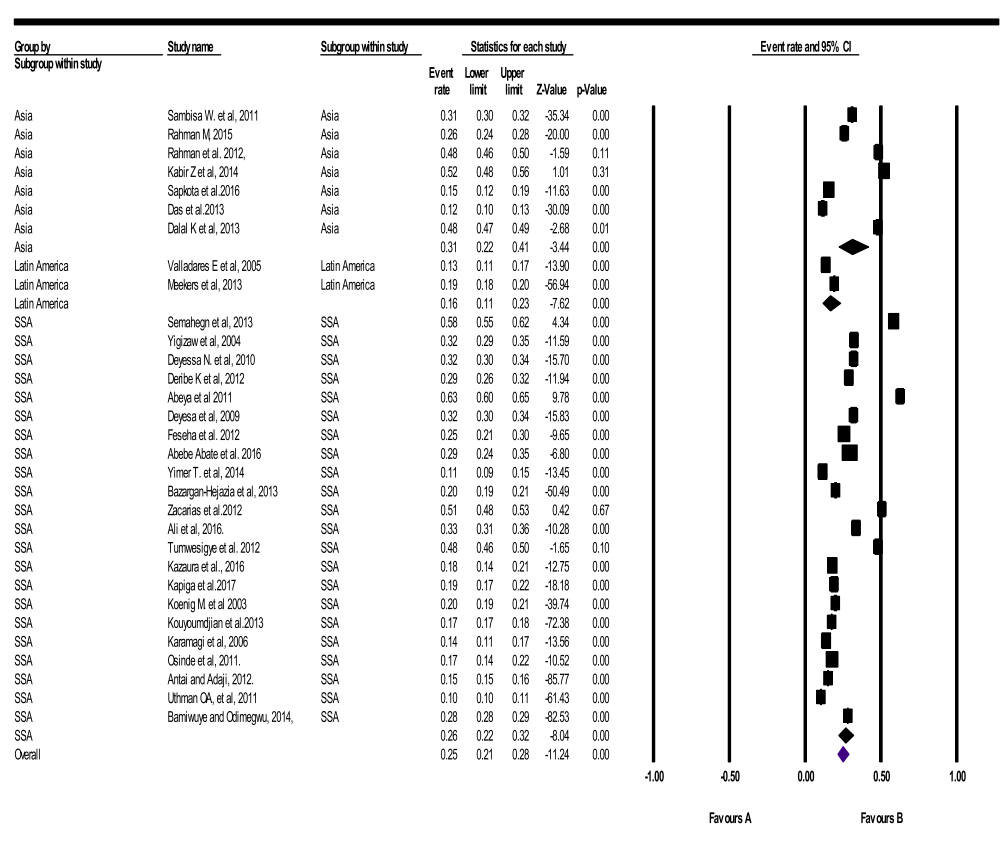

Meta Analysis

Heterogeneity: Tau $^{2}=0.359$, Standard Error $=0.174, d f=30(p<0.000) ; I^{2}=99.61 \%$ Test overall: $Z=-9.347(p<0.000)$

Fig. 7 Forest plot of the current physical intimate partner violence against women $(n=31)$

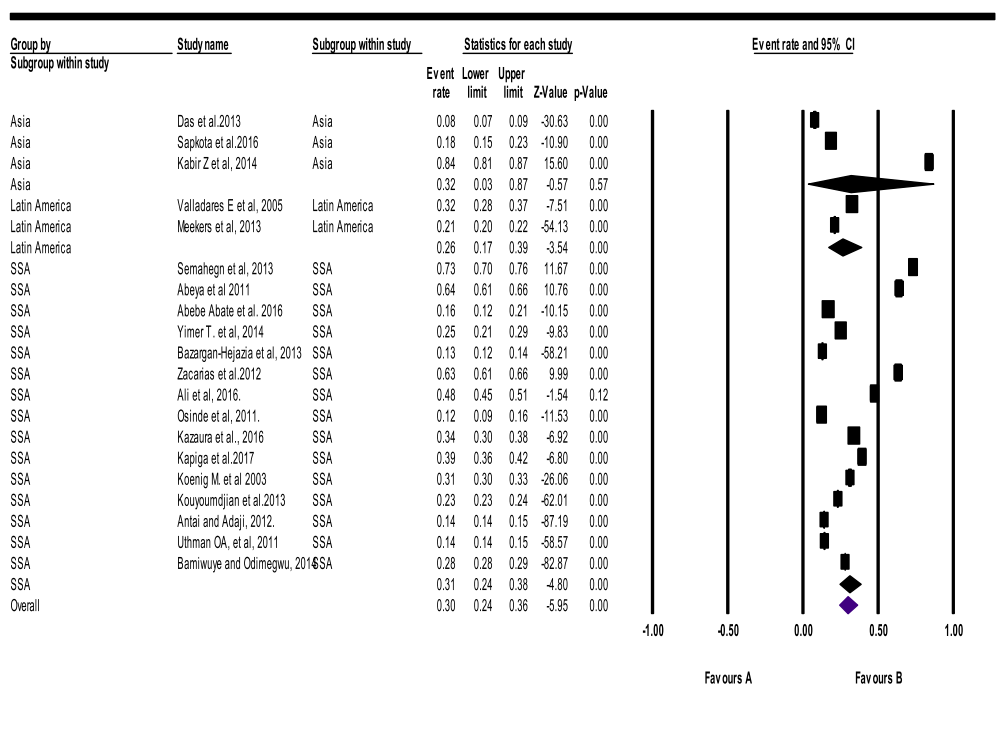

Neta Aralysis

Heterogeneity: Tau $^{2}=0.42$, Standard Error $=0.26, \mathrm{Df}=19(p<0.000) ; I^{2}=99.71 \%$

Test overall: $Z=-5.95(p<0.000)$

Fig. 8 Forest plot of the current psychological intimate partner violence against women $(n=20)$ 


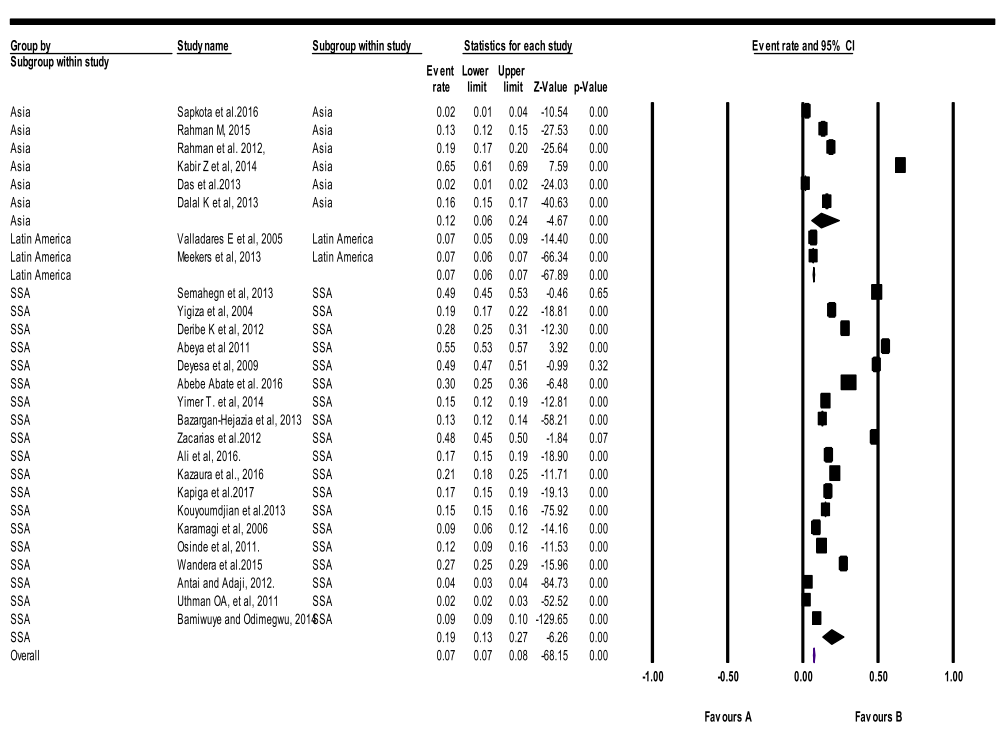

MetaAnaysis

Heterogeneity: Tau $^{2}=0.955$, Standard Error $=0.468, d f=26(p<0.000) ; I^{2}=99.73 \%$

Test overall: $Z=-6.779(p<0.000)$

Fig. 9 Forest plot of the current sexual intimate partner violence against women $(n=27)$

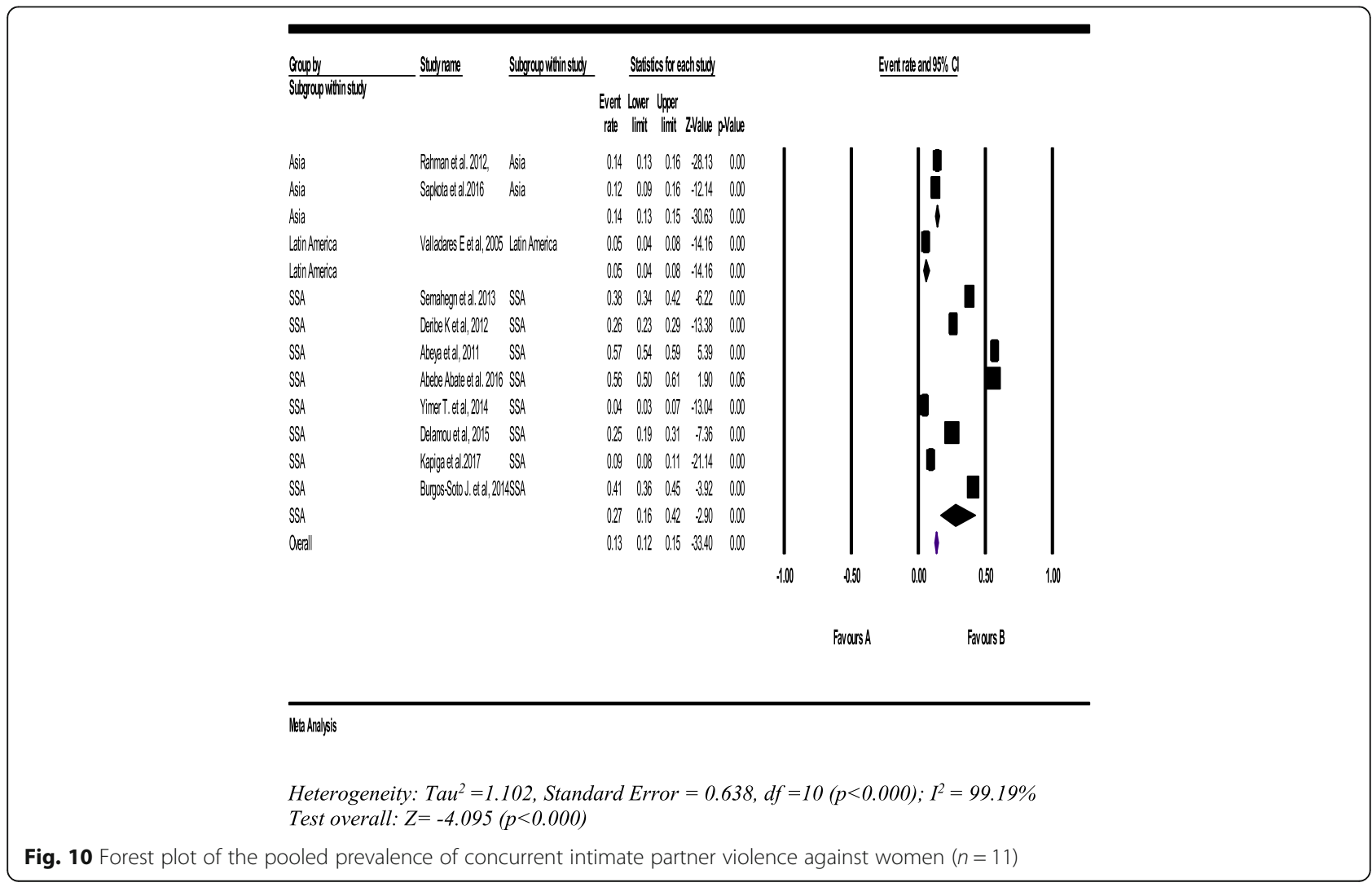


during their childhood were more likely to report lifetime and current IPV than their counterparts $[25,53$, $61,72,79]$. Likewise, in some studies, women whose husbands were beaten by someone in their family during their childhood were two times more likely to report experiences of IPV than those who were not beaten during childhood [53, 72, 79]. In addition, women's exposure to physical IPV was 5 to 6 times more likely to be higher on women whose husband having witnessed that their mothers being beaten by their fathers than women whose husband had no history (witness) of maternal IPV [51, 66, 70]. Furthermore, in one study, IPV was associated with women who had a history of sexual abuse during childhood, adolescence or even an early age of first sex [60].

Husbands' controlling behaviors and mental health condition IPV was higher among women who were afraid of their husbands [53, 80]. Women whose husbands had controlling, hostile and or rude behaviors were almost three to four times more likely exposed to any type of IPV than their counterparts [47, 53, $68,77,79]$. Women who had high levels of emotional distress were associated with IPV [82]. Furthermore, women whose husbands previously engaged in physical fight were 3.5 times more likely to experience IPV than others. In a similar way, women with an unhealthy mental status were two times more likely to experience IPV than women with a healthy mental status [47].

Husband alcohol consumption Women whose husbands' drank alcohol were more likely to experience IPV than women whose husbands did not drink alcohol. As we found from several studies, husbands' alcohol consumption is the most commonly reported factor associated with IPV $[6,25,49-51,56,60,62-64,66,70$, $79,80]$. Furthermore, in one study, IPV was significantly associated with husband's use of psychoactive substances [66].

Pregnancy status In three studies, pregnant women with high parities had a higher probability of experiencing lifetime IPV than non-pregnant women [48, $49,66]$. Furthermore, in one study, women whose pregnancies were undesired by their partners was six times more likely to have risk of current IPV than pregnancy desired by partner [64]. Likewise, in two studies, the likelihood of women's experience of lifetime IPV was consistently higher as the number of children increased $[48,54]$.

\section{Relationship factors}

Women's decision making status Decision making power was a predictor of IPV [49]. Generally, the odds of IPV was less by $50 \%$ for women who had an equal say in household decision-making. Sexual violence was $35 \%$ less likely to occur among women who had a share in household decision-making [25]. Interestingly, the probability of women being physically abused decreased by $8.2 \%$ for those women whose husbands dominated household decision-making, whereas wifedominance in household decision-making had a marginal effect on physical violence [54]. However, women who decided on spending their own or husband's earning with a joint decision-making approach in view of their own healthcare utilization, large household purchase, or contraceptive use were less likely to be victims of IPV than women who made decisions by themselves [53].

Infidelity and lack of satisfaction in marriage In four studies, women whose husbands had engaged in extramarital sex or had multiple sexual partners (unfaithful) were two times more likely to be at risk of IPV than their counterparts $[51,62,72,80]$. Yet, exposure to physical IPV was associated with being unfaithful. Women who agreed that a woman was obliged to have sex with her husband had a lower risk of exposure to physical IPV than those who disagreed [51]. Women who had poor relationships with their husbands were 2.6 times more likely to experience physical IPV [58]. Furthermore, women who had a satisfaction in their marriage were noted to face a low risk of IPV [62]. Sexual IPV was higher among women whose partner were jealous if they talked with other men, suspected them of unfaithfulness, did not permit them to meet even female friends, limit their contact with family [80]. Those women who did not believe a wife could do anything if a husband wanted a girlfriend were three times more likely to be exposed to physical IPV [68]. In the same view, women who could refuse sex with their partners or ask their husbands to use condoms were two times more likely to be victims of IPV than their peers who could not [53]. Women who had worries on issues about their daily activities and did not discuss them with their partners were more likely to experience IPV than women who did discuss their issues [66].

Type of marriage In five studies, the type of marriage was significantly associated with IPV. Women who were married or cohabitated by abduction; women married to distant relatives; women with a polygamous partner or in a polygamous marriage; payment of dowry and marriage undergone without ceremony 
were more likely to experience IPV than their counterparts $[27,48,50,61,79]$.

Duration of marriage In two studies, this factor was significantly associated with higher experience of physical abuse. Women who were married for 5-9 years (OR, 3.8) or ten or more years (OR, 3.7) were at higher risk of being abused than women who were married for less than 5 years $[48,60]$.

Wealth index and economic status IPV and wealth index had an association but an inconsistent relationship across the wealth quintiles. In six studies, women belonging to the poorest wealth index categories were most likely to be exposed to IPV than women in the rich wealth index $[51,52,54,63,65,74]$. Other studies, microfinance program membership was associated with a two-three-fold increase in exposure to IPV [65], as were family and financial problems associated with IPV $[66,79]$.

\section{Community level factors}

Presence of the traditional gender norms In two studies, women's exposure to IPV were more likely to be high in communities who adhered to traditional patriarchal gender norms or beliefs and supported (accepted) attitudes towards wife beating [51, 54]. Meanwhile, women who agreed that "a good wife obeys her husband" and/ or "a man should show who the boss is" were more likely to experience sexual IPV than women who disagreed. In addition, women who agreed that a woman had no reason to refuse sex with her husband were three times more likely to be exposed to IPV as compared to who agreed for some reasons [51]. In addition, women who worked outside the home but whose husbands did not make enough money had an increased risk of IPV by $5.2 \%$ than women whose husbands made enough money [54].

Community attitude towards wife-beating Communities whose attitudes supported IPV [66] by thinking that justified wife-beating is acceptable [60], or encouraged societal gender beliefs or norms [54], reflected relationship control, and relationship inequalities $[40,51]$ were significantly associated with women's experience of IPV.

\section{What were the key recommendations from the studies? Transformation of community's traditional gender norms}

In seven studies, undertaking a massive and intensive information, education and communication (IEC) approach is a recommended strategy on transforming a community's culture and traditional gender norms in order to enhance gender equality $[25,27,38,47,49,51,61]$.
Similarly, in eight studies, there is a need to employs comprehensive and culturally acceptable approaches including medical (psychiatric) counseling, community mobilization, gender advocacy and effective development of IEC to dispel myths, misconceptions, negative traditional norms and beliefs, gender inequality and to reduce the costs of IPV [6, 40, 54, 68, 70, 72, 75, 79].

\section{Human right based approach}

In one study, community level awareness of human rights as well as advocacy for women's rights is crucial [67]. In four studies, more investments in IPV prevention strategies are needed to address the intergenerational transfer of deeply entrenched cultural-norms which support male dominance and gender inequality $[57,66,73,90]$.

\section{Stakeholder engagement}

The urgent attention of policymakers, stakeholders, professionals and other concerned bodies is needed at all levels of society. Stakeholders should design interventions targeting behavioral and social factors which can help to prevent IPV [79]. Likewise, resources should be mobilized by policy-makers, public health experts, researchers and other stakeholders to prevent IPV [48, 59, 63, 72]. Advocacy is very important and can be done as religious institutions, media, government and non-governmental associations encourage gender equality by $[66,67,70,73]$.

\section{Policy formulation and legal framework}

The issue of gender equality, women's rights and legal sanctions need due attention during policy formulation and endorsement of laws to prevent VAW are crucial. In many instance of VAW, the punishment to perpetrators were light and not commensurate with the offence victims filed. The law should be more responsive to VAW to help address this challenge [25, 68]. Perhaps, survivors are encouraged to disclose their experience of IPV to people who are in position or have an autonomy, and implementing the existing law for punishment [70]. Policymakers should take immediate action to break hierarchical barriers between spouses, and promote gender equality while amending the existing laws or formulating new policies [52, 53, 75]. However, evidence based efforts are needed to re-enforce legal rights or existing laws and policies and ensure their effective implementation to prevent and respond to VAW $[54,57,67]$.

\section{Women empowerment}

Six studies have recommended that building women's capacity through education, employment, income and other economic opportunities, and addressing imbalance of power between men and women are crucial to 
prevent IPV [25, 47, 52, 53, 56, 79]. Likewise, promising public health strategies (increasing awareness of the consequences of IPV, strengthening the self-esteem of women and girls and promoting equity in marital relationships) are needed to change attitudes towards gender inequality, and are essential to avert IPV [47, 70, 79]. Furthermore, addressing household poverty-wealth comprehensively [74], enhancing the safety of women, promoting fertility control methods and women's reproductive health service [40] are some other recommended interventions to prevent and control IPV.

\section{Intervention integration}

Innovative strategies are needed to provide support and counselling to IPV survivors, who are rarely assisted by health care professionals [82]. Research findings have strongly recommended that IPV prevention interventions be integrated with community health programs; reproductive health and other health services to be more comprehensive, close to household level and accessible to IPV survivors [27, 49, 53, 67, 70]. Integration may help to enhance medical screening of survivors for STI including HIV, provide male partner counseling and other health care support. Furthermore, the authors [38, $48,67,78]$ recommended that reproductive health service providers should be encouraged to advocate for IPV and mental health screening during antenatal care.

\section{Engaging men and other influential persons on IPV prevention}

Research findings have proposed that community programs that have a couple-centered approach are needed to promote non-violent masculinity values and norms $[47,51,58]$. Moreover, working with men is a winwin-approach to prevent IPV. Efforts are needed to focus societal, community, relationship and individual level approaches which engage men to promote men's non-violent behavior and gender equality and to minimize infidelity [51, 62, 67]. In addition, interventions addressing IPV should place more emphasis on reducing partners' controlling behaviors and to prevent men's alcohol drinking habits [56, 62, 66, 80]. Furthermore, involving mother-in laws would be a significant move [47]. Also, community health workers could be active players in raising community awareness about IPV [27, 49].

\section{What are the proven evidence?}

We systematically selected eight interventional studies that had been conducted in LLMICs [83-90]. The detail of GRADE for the summary of evidence for different outcomes is attached as an Additional file 6. In two studies, the social accepting attitude of IPV was lowered by community mobilization intervention. Women's attitude towards sex refusal when necessary was 1.3 times more likely higher in the community mobilization intervention than control group. Likewise, current physical, sexual and concurrent IPV were lowered in the intervention group by $52,24 \%$, and 435 respectively than the control group. In addition, women experiencing IPV in intervention communities were more likely to receive supportive community responses. [83, 90]. In one study, the community-level normative attitude towards physical IPV and IPV acceptability norms were improved in the intervention group than the control. In addition, men's suspicion of their partner for infidelity and communication about sex were improved [90]. Similarly, in one study, community engagement and group education combined interventions reduced IPV almost by $20 \%$ while the CE-only group reduced it by $23 \%$, and enhanced gender equitable norms [85].

In the two interventional studies which is mainly focused on women's economic empowerment through a village loan and saving association approach, women in the combined groups were significantly less likely to report economic abuse than control group (OR, 0.39, $95 \%$ CI: $0.25,0.60)[84,86]$. In one study, while attitude towards refusal of sex did not significantly change, women in the combined (VLSA and GDG) intervention group reported a lower experience of current IPV and also acceptance of justified wife-beating than VLSA alone, but it was not statistically significant [84]. In one study, women who got married when they were children were $46 \%$ less likely to report physical and or sexual violence in the combined intervention group than the control. The reduction was however, not statistically significant in the overall IPV [86].

Women's attitudes about IPV and power relationships were associated with their IPV experience. In one study, women who report violence was ever justified if a woman refuses sex were two times more likely to experience IPV than control group. Furthermore, women in joint (both partners) sexual decision making relationships were $30 \%$ less likely to report IPV as compared to women whose partners controlled sexual decision-making. Notably, women were $57 \%$ less likely to report IPV when both partners had equal power [87]. However, women's economic empowerment was doubled for those women in the safe home and respect for everyone (SHARE) intervention group. Likewise, women in the intervention group were $20 \%$ less likely to experience IPV than those in the control group. Nevertheless, SHARE had no significant effect on emotional IPV, men's behavior (perpetration) [88], overall IPV, women's autonomy and women's attitude towards gender norms [89].

\section{Discussion}

This systematic review and meta-analysis determined the prevalence of domestic IPV and its types, associated 
factors, effective interventions and key recommendations to prevent domestic VAW. We found out that the pooled prevalence of lifetime IPV was 55\% (95\% CI: 52, $59 \%)$. Of these, lifetime physical, psychological and sexual violence were 39, 45 and 20\%, respectively. Furthermore, the pooled prevalence of current IPV was 38\% (95\% CI: 33.0, 43\%). Of these, prevalence of current physical, psychological and sexual violence were 25, 30 and $7 \%$, respectively. In addition, the pooled prevalence of women's experience of concurrent IPV was 13\% (95\% CI: 12, 15\%). This finding is consistent with the WHO's global estimates and multicounty study whose findings indicated that one-in- three women experienced domestic VAW in their lifetime $[1,98,99]$.

As evidence shows that IPV was significantly associated with educational level, place of residence, economic status, having witnessed abuse during childhood, husbands' having controlling behavior, husbands' alcohol consumption, pregnancy status and parity. Notwithstanding, sexual violence was common among women who had husbands younger than 35 years. Furthermore, women in unfaithful relationships and unsatisfied marriages as well as women who married early and have experienced forced first sex, short duration of marital life, and poor mental health had a higher risk of experiencing IPV. In addition, the presence of traditional gender-norms and wife-beating accepting attitudes were linked with a high risk of domestic violence. This finding is also consistent with the ecological model formulated in 1998 [97, 100] which is very applicable in low and lower-middle income settings and is targeted at the deep rooted causes.

This systematic review found out that IPV prevention should focus on community culture or traditional gender-norm transformation; stakeholders' engagement; women empowerment (capacity building); engaging men and other influential people (mother and/ or father in-laws, sister-in-law, neighbors); intervention should focus on service integration with other relevant sectors (mainly health sector for screening and other care and support); policy formulation and provision of legal framework and implementation of human right based approaches. This finding is consistent with other reviews that recommended focus on the structural drivers of unequal power in relationships to prevent VAW [98, 100-102].

We included observational and interventional studies. However, we interpreted the findings to meet our review objectives. Nevertheless, we did not mix-up the findings of the observational and interventional studies. Though, this systematic review and meta-analysis used relatively comprehensive search of the major databases; included both quantitative and qualitative studies; published and unpublished studies and sub-group analysis by setting and violence types, it had some limitations. One of the main limitations was the inconsistent definition of IPV across some studies. Hence, we used both IPV and domestic VAW synonymously. The second limitation of this systematic review and meta-analysis is that it did not carry out quantitative synthesis on the factors associated with domestic VAW due to the high heterogeneity between included studies. However, it is difficult to find absolutely homogeneous studies in terms of setting, method, analysis and interpretation.

\section{Implication of the review}

Domestic violence against women is a common women's life experience and mostly perceived as minor and socially tricky by many governments. However, its consequences have a devastating impact on national gross domestic product and costs much higher than the budget allotted for primary education. Hence, generating evidence on the prevalence, associated factors and identifying effective interventions applicable in poorly resourced settings is very crucial. This systematic review and meta-analysis can give critical insight about VAW, associated factors, and effective interventions. Therefore, concerned stakeholders can use the findings of this study as main evidence to inform policymakers, program designers and local planners construct and for implement policies to prevent IPV in LLMICs.

\section{Conclusion}

Both lifetime and current domestic IPV are still high in LLMICs. More than half of the women in the studies had experienced lifetime domestic IPV, and almost one-third of the women had experienced current IPV. In addition, almost one-in-ten women experienced more than one type of IPV concurrently. Domestic IPV is a complex public health and human rights violation which is associated with factors at the individual, relationship, community and entire system level. However, most of the associated factors are preventable. Interventions integrating legal framework and programs that focus on transformation of traditional gender-norms are most important to prevent IPV. Community mobilization and awareness creation to transform gender-norm reduced IPV by half. However, the economic empowerment intervention had reduced some influences on women (reduced economic abuse), but it was not statistically significant in the prevention of IPV. Therefore, we suggest that researchers, program planners, policy makers, clinicians and other concerned stakeholders should invest in the implementation of gender-norms focused on community based interventions to prevent IPV. 


\section{Additional files}

Additional file 1: PRISMA checklist. (DOC $85 \mathrm{~kb}$ )

Additional file 2: 2-1 \& 2-1-1: Searching strategy on PubMed database. 2-2 Searching strategy on Medline database. 2-3 Searching strategy on EMBASE database. 2-4 Searching strategy on CNHAL database. (ZIP 2206 kb)

Additional file 3: Studies quality assessment using JBI critical appraisal checklist. (DOCX $24 \mathrm{~kb})$

Additional file 4: 4-1 Heterogeneity between studies illustration using funnel plot. 4-2 Risk of bias (ROB) assessment. (ZIP 69 kb)

Additional file 5: The extracted data stored on Microsoft Excel sheet for met-analysis. (XLSX $19 \mathrm{~kb}$ )

Additional file 6: GRADE for the summary of evidence for different outcomes. (DOCX $18 \mathrm{~kb}$ )

Additional file 7: Confirmation letter for funding. (PDF $1930 \mathrm{~kb}$ )

\section{Abbreviations}

AOR: Adjusted Odds Ratio; CE: Community engagement; Cl: Confidence interval; GDG: Gender Dialogue Group; IEC: Information, education and communication; IPV: Intimate partner violence; JBI: Joana Briggs Institute; LLMICS: Low and lower-middle income countries; SHARE: Safe Home and Respect for Everyone; SSA: Sub-Saharan Africa; TDR: Tropical Disease Research; VAW: Violence against women; VSLA: Village Save and Loan Association; WHO: World Health Organization

\section{Acknowledgements}

We would like to thank School of Public Health, University of Ghana (Ghana), TDR/WHO and Haramaya University (Ethiopia) for their support.

\section{Funding}

This work has been funded by TDR, the Special Programme for Research and Training in Tropical Diseases, which is hosted at the World Health Organization and co-sponsored by UNICEF, UNDP, the World Bank and WHO. The grant number for the University of Ghana is B40300 (see Additional file 7).

\section{Availability of data and materials}

The data that support the review findings of this study are available upon submitting a reasonable request to the corresponding author (see Additional file 5).

\section{Authors' contributions}

AS*, KT, AM, and AA conceived and designed the review. AS* carried out activities from inception to the draft of the manuscript and is the guaranto of the review. AS* and GT developed the search strings, selection, analysis and interpretation. $A S^{*}, K T, A M, N A$, GT and $A A$ rigorously review the manuscript. All authors read and approved the final version of the manuscript.

\section{Ethics approval and consent to participate}

Not applicable.

\section{Consent for publication}

Not applicable.

\section{Competing interests}

The authors declare that they have no competing interests.

\section{Publisher's Note}

Springer Nature remains neutral with regard to jurisdictional claims in published maps and institutional affiliations.

\section{Author details}

${ }^{1}$ Department of Population, Family and Reproductive Health, School of Public Health, College of Health Science, University of Ghana, Legon, Accra, Ghana. ${ }^{2}$ College of Health and Medical Sciences, Haramaya University, Po.
Box 235, Harar, Ethiopia. ${ }^{3}$ Population Council/Ghana, Yiyiwa Drive, Accra, Ghana.

Received: 7 June 2018 Accepted: 24 April 2019

Published online: 01 July 2019

\section{References}

1. WHO. Global and regional estimates of violence against women: prevalence and health effects of intimate partner violence and non-partner sexual violence. Geneva: World Health Organization; 2013. www.who.int/ reproductivehealth.

2. Ellsberg M, Jansen HAFM, Heise L, Watts CH, García-moreno C, Study WHOM. Intimate partner violence and women's physical and mental health in the WHO multi-country study on women's health and domestic violence: an observational study. Lancet. 2008:371:1165-72.

3. Watts C, Zimmerman C. Violence against women: global scope and magnitude: violence against women I. Lancet. 2002;359:1232-7.

4. Inge Baumgarten AE. Ending violence against women and girls; reduction and prevention of gender based-violence as contribution to the protection of human rights and to development: African division. 2003.

5. Jewkes RK, Levin JB, Penn-kekana LA. Gender inequalities, intimate partner violence and HIV preventive practices: findings of a south African crosssectional study. Soc Sci Med. 2003;56:125-34.

6. Koenig MA, Lutalo T, Zhao F, Nalugoda F, Wabwire-mangen F, Kiwanuka N, et al. Domestic violence in rural Uganda: evidence from a community-based study. Bull World Health Organ. 2003:81:53-60.

7. Kouyoumdjian FG, Findlay N, Schwandt M, Calzavara LM. A systematic Review of the relationships between intimate partner violence and HIV/ AIDS. PLoS One. 2013;8(11):e81044.

8. Benefits E, Equality G. Sexual and reproductive health and rights (SRHR) and the Post-2015 development agenda, vol. 1; 2015.

9. WHO. Addressing violence against women and achieving the Millennium Development Goals. Geneva: World Health organization; 2005. http://www. who.int/gender/en.

10. Jamison DT, Summers LH, Alleyne G, Arrow KJ, Berkley S, Binagwaho A, et al. Global health 2035: a world converging within a generation. Lancet. 2014:382(9908):1898-955.

11. AU. Maputo Plan of Action 2016-2030 for the Operationalization of the Continental Policy Framework for Sexual and Reproductive Health and Rights, Universal Access to Comprehensive Sexual and Reproductive Health Services in Africa MAPUTO. African Union. Addis Ababa; Ethiopia. 2016. http://www.au.int

12. Remme M, Siapka M, Vassall A, Heise L, Jacobi J, Ahumada C, et al. Review article The cost and cost-effectiveness of gender-responsive interventions for HIV : a systematic review. J Int AIDS Soc. 2014;17:19228.

13. PRB, TIGWG (IGWG). Gender-Based Violence and Reproductive Health \& HIV/ AIDS. Summary of technical update. Population Reference Bureau, Washington, DC 20009-5728; 2002. Available from: www.prb.org or www. igwg.org.

14. Dhakal L. Berg-beckhoff G., Aro AR. Intimate partner violence (physical and sexual) and sexually transmitted infection: results from Nepal Demographic Health Survey 2011. Int J Women's Heal. 2014:6:75-82.

15. Pallitto CC, Campo PO. Community level effects of gender inequality on intimate partner violence and unintended pregnancy in Colombia: testing the feminist perspective. Soc Sci Med. 2005:60:2205-16 Elsevier.

16. WHO. Violence against women and HIV/AIDS: critical intersections intimate partner violence and HIV / AIDS. WHO bulletin Series. 2004;1:1-9. Available from: genderandhealth@who.int

17. WHO. Violence against women; intimate partner violence and sexual violence. Geneva: World Health Organization. 2015. https://www.who.int/ news-room/fact-sheets/detail/violence-against-women.

18. Agrawal A, Bloom SS, Suchindran C, Curtis S, Angeles G. Gender-based power and couples' HIV risk in Uttar Pradesh and Uttarakhand, North India. HHS public access. Int Perspect Sex Reprod Health. 2015:40(4):196-205.

19. Thomson DR, Bah AB, Rubanzana WG, Mutesa L. Correlates of intimate partner violence against women during a time of rapid social transition in Rwanda: analysis of the 2005 and 2010 demographic and health surveys. BMC Womens Health. 2015;15(96).

20. Mukanangana F, Moyo S, Zvoushe A, Rusinga O. Gender based violence and its effects on Women's reproductive health: the case of Hatcliffe, Harare, Zimbabwe. Afr J Reprod Health. 2014;18(1):110-22. 
21. Feder G, Howard LM, Trevillion K. Experiences of domestic violence and mental disorders: a systematic Review and Meta-analysis. PLoS One. 2012; 7(12):e51740.

22. Unifem A. Domestic violence fact sheet. A 2010 Lenten Study compiled by the world Council of Churches, the world student Christian Federation and the world YWCA; 2010.

23. Pico-alfonso MA. Psychological intimate partner violence: the major predictor of posttraumatic stress disorder in abused women. Neurosci Biobehav Rev. 2005;29:181-93.

24. Kalichman SC, Simbayi LC, Cloete A, Clayford M, Mxoli M, Smith G, Integrated Gender-Based Violence and HIV Risk Reduction Intervention for South African Men. NIH Public Access. Prev Sci. 2011;10(3):260-9.

25. Yigzaw T, Yibrie A, Kebede Y. Domestic violence around Gondar in Northwest Ethiopia. EthiopJHealth Dev. 2004;18(3):133-9.

26. Guruge S, Bender A, Aga F, Hyman I, Tamiru M, Hailemariam D, et al. Towards a global interdisciplinary evidence-informed practice: intimate partner violence in the Ethiopian context. Int Sch Res Network. ISRN Nursing. Volume 2012, Article ID 307271. https://doi.org/10.5402/2012/ 307271. https://www.ncbi.nlm.nih.gov/pmc/articles/PMC3363987/pdf/ISRN. NURSING2012-307271.pdf.

27. Abate BA, Wossen BA, Degfie TT. Determinants of intimate partner violence during pregnancy among married women in Abay Chomen district, Western Ethiopia: a community based cross sectional study. BMC Womens Health. 2016;16:16.

28. Dunkle KL, Jewkes RK, Brown HC, Gray GE, Mcintryre JA, Harlow SD. Genderbased violence, relationship power, and risk of HIV infection in women attending antenatal clinics in South Africa. Lancet. 2004;363:1415-21.

29. Shi C, Kouyoumdjian FG, Dushoff J. Intimate partner violence is associated with HIV infection in women in Kenya: a cross-sectional analysis. BMC Public Health. 2013:13:512.

30. Onsomu EO, Abuya BA, Okech IN, Rosen DL, Duren-Winfield V, Simmons AC. Association between domestic violence and HIV serostatus among married and formerly married women in Kenya. NIH Public Access Heal Care Women Int. 2015;36(2):205-28.

31. Li Y, Marshall CM, Rees HC, Nunez A, Ezeanolue EE, Ehiri JE. Intimate partner violence and HIV infection among women: a systematic review and metaanalysis. J Int AIDS Soc. 2014;17:18845.

32. Harling G, Msisha W, Subramanian SV. No Association between HIV and Intimate Partner Violence among Women in 10 Developing Countries. PLoS One. 2010;5(12):e14257. https://doi.org/10.1371/journal.pone.0014257.

33. Decker MR, Seage GR III, Hemenway D, Raj A, Saggurti N, Balaiah D, Silverman JG. Intimate partner violence functions as both a risk marker and risk factor for Women's HIV infection: findings from Indian husband-wife dyads. NIH public access. J Acquir Immune Defic Syndr. 2009;51(5):593-600

34. Maman S, et al. Intersection of Intimate Partner Violence and HIV in Women. Soc Sci Med. 2000;50(4):459-78.

35. Burgos-Soto J, Orne-Gliemann J, Encrenaz G, Patassi A, Woronowski , Benjamin Kariyiare B. et al. Intimate partner sexual and physical violence among women in Togo, West Africa: Prevalence, associated factors, and the specific role of HIV infection. Global Health Action. 2014;7:23456. http://dx. doi.org/10.3402/gha.v7.23456.

36. Sigbeku O, Fawole O, Ogunniyan T. Experiece of intimate partner violence as a predictor of sexually transmitted infections among married women Nigeria. Ann Ibd Pg Med. 2015;13(1):6-16.

37. Pallitto CC, O'Campo P. And unintended pregnancy: analysis of a National Sample from Colombia. Int Fam Plan Perspect. 2004;30(4):165-73.

38. Rahman M. Intimate partner violence and termination of pregnancy: a cross-sectional study of married Bangladeshi women. Reprod Health. 2015;12:102

39. Nguyen PH, Van NS, Quang M, Nguyen NT, Keithly SC, Mai LT, et al. The association and a potential pathway between gender-based violence and induced abortion in Thai Nguyen province, Vietnam. Glob Health Action. 2012;5(19006):11.

40. Antai D, Adaji S. Community-level influences on women's experience of intimate partner violence and terminated pregnancy in Nigeria: a multilevel analysis. BMC Pregnancy Childbirth. 2012;12:128.

41. Rahman M, Nakamura K, Seino K, Kizuki M. Intimate partner violence and use of reproductive health services among married women: evidence from a national Bangladeshi sample. BMC Public Health. 2012; 12:913.
42. Muralidharan A, Fehringer J, Pappa S, Rottach E, Das M, Mandal M. Transforming gender norms, roles, and power dynamics for evidence from a health programs in Low and Middle Income Countries. Washington DC; 2015.

43. Moher D, Shamseer L, Clarke M, Ghersi D, Liberati A, Petticrew M, et al. Preferred reporting items for systematic review and meta-analysis protocols (PRISMA-P) 2015 statement. Syst Rev. 2015;4:1. https://doi.org/10.1186/20464053-4-1.

44. RUTGERS the state University of New Jersey. George F. Smith Library of the Health Sciences. EndNoteX8.0.1(Bld 10444), Cite While You Write TM Patented technology U.S patent number 8,092,241. University of Ghana: 3091850168. http://www.libraries.rutgers.edu/sites/default/files/smith/pdf/ EndNoteBasic.pdf.

45. Fantom N, Serajuddin U. The World Bank's classification of countries by income, Policy Research Working paper 7528: World Bank Group; 2016.

46. Munn Z, Moola S, Lisy K, Riitano DTC. Methodological guidance for systematic reviews of observational epidemiological studies reporting prevalence and incidence data. The Joanna Briggs institute critical appraisal tools for use in JBI systematic reviews checklist for prevalence studies. Int J Evid Based Heal. 2015;13(3):147-53. http://joannabriggs.org/research/criticalappraisal-tools.html.

47. Sapkota D, Bhattarai S, Baral D, Pokharel PK. Domestic violence and its associated factors among married women of a village development committee of rural Nepal. BMC Res Notes. 2016;9:178.

48. Fikree FF, Jafarey SN, Korejo R, Afshan A, Durocher JM. Original article intimate partner violence before and during pregnancy : experiences of postpartum women in Karachi, Pakistan. JPMA. 2006;56:252-7.

49. Semahegn A, Belachew T, Abdulahi M. Domestic violence and its predictors among married women in reproductive age in Fagitalekoma Woreda, Awi zone, Amhara regional state, North Western Ethiopia. Reprod Health. 2013; 10:63.

50. Ali AA, Yassin K, Omer R. Domestic violence against women in eastern Sudan. BMC Public Health. 2014;11:36.

51. Hayati EN, Högberg U, Hakimi M, Ellsberg MC, Emmelin M. Behind the silence of harmony: risk factors for physical and sexual violence among women in rural Indonesia. BMC Womens Health. 2011;11(1):52.

52. Doku DT, Asante KO. Women's approval of domestic physical violence against wives: analysis of the Ghana demographic and health survey. BMC Women's Health. 2015;15(120). https://doi.org/10.1186/s12905-0150276-0.

53. Dalal K, Wang S, Svanström L. Intimate partner violence against women in Nepal: an analysis through in- dividual, empowerment, family and societal level factors. J Res Heal Sci J. 2014;14(4):251-7.

54. Sambisa MW, Angeles G, Lance P, Naved RT, Thornton J. Prevalence and correlates of physical spousal violence against women in slum and nonslum areas of urban Bangladesh. J Interpers Violence. 2011;26:13.

55. Rapp D, Zoch B, Khan MMH, Pollmann T, Krämer A. Association between gap in spousal education and domestic violence in India and Bangladesh. BMC Public Health. 2012;12:467.

56. Tumwesigye NM, Kyomuhendo GB, Greenfield TK, Wanyenze RK Problem drinking and physical intimate partner violence against women: evidence from a national survey in Uganda. BMC Public Health 2012;12:399.

57. Delamou A, Samandari G, Camara BS, Traore P, Diallo FG, Millimono S, et al. Prevalence and correlates of intimate partner violence among family planning clients in Conakry, Guinea. BMC Res Notes. 2015;8:814.

58. Kabir ZN, Nasreen H, Edhborg M. Intimate partner violence and its association with maternal depressive symptoms 6-8 months after childbirth in rural Bangladesh. Glob Health Action. 2014;7:24725.

59. Kazaura MR, Ezekiel MJ, Chitama D. Magnitude and factors associated with intimate partner violence in mainland Tanzania. BMC Public Health. 2016;16:494

60. Kouyoumdjian FG, Calzavara LM, Bondy SJ, Campo PO, Serwadda D, Nalugoda F, et al. Risk factors for intimate partner violence in women in the Rakai community cohort Study, Uganda, from 2000 to 2009. BMC Public Health. 2013;13(1).

61. Deyessa N, Berhane Y, Ellsberg M, Emmelin M, Kullgren G, Ho U. Violence against women in relation to literacy and area of residence in Ethiopia. Glob Health Action. 2010;3:2070.

62. Karamagi CAS, Tumwine JK, Tylleskar T, Heggenhougen K. Intimate partner violence against women in eastern Uganda: implications for HIV prevention. BMC Public Health. 2006;6:284 
63. Das S, Bapat U, More NS, Alcock G, Joshi W, Pantvaidya S, et al. Intimate partner violence against women during and after pregnancy: a crosssectional study in Mumbai slums. BMC Public Health. 2013;13:817.

64. Yimer T, Gobena T, Egata G, Mellie H. Magnitude of domestic violence and associated factors among pregnant women in Hulet Ejju Enessie District, Northwest Ethiopia. Hinadawi-Advances Public Heal. 2014;2014:484897.

65. Dalal K, Dahlström Ö, Timpka T. Interactions between micro fi nance programmes and non-economic empowerment of women associated with intimate partner violence in Bangladesh: a cross-sectional study. BMJ Open. 2013;3(e002941):13-5.

66. Owoaje ET, Olaolorun FM. Women at risk of physical intimate partner violence: a cross- sectional analysis of a low-income Community in Southwest. Afr J Reprod Health. 2012;16(1):43-53.

67. Laisser RM, Nyström L, Lugina HI, Emmelin M. Community perceptions of intimate partner violence - a qualitative study from urban Tanzania. BMC Womens Health. 2011;11:13.

68. Deribe K, Beyene BK, Tolla A, Memiah P, Biadgilign S. Magnitude and correlates of intimate partner violence against women and its outcome in Southwest Ethiopia. PLoS One. 2012;7(4):e36189.

69. Kapiga S, Harvey S, Muhammad AK, Stöckl H, Mshana G, Hashim R, et al. Prevalence of intimate partner violence and abuse and associated factors among women enrolled into a cluster randomised trial in northwestern Tanzania. BMC Public Health. 2017;17:190.

70. Feseha G, Abebe G, Gerbaba M. Intimate partner physical violence among women in Shimelba refugee camp, northern Ethiopia. BMC Public Health. 2012;12:125.

71. Osinde MO, Kaye DK, Kakaire O. Intimate partner violence among women with HIV infection in rural Uganda: critical implications for policy and practice. BMC Womens Health. 2011;11:50.

72. Yigzaw T, Berhane Y, Deyessa N, Kaba M. Perceptions and attitude towards violence against women by their spouses: a qualitative study in Northwest Ethiopia. EthiopJHealth Dev. 2010;1:39-45.

73. Uthman OA, Moradi T, Lawoko S. Are individual and community acceptance and witnessing of intimate partner violence related to its occurrence? Multilevel structural equation model. PLoS One. 2011;6(12):e27738.

74. Bamiwuye SO, Odimegwu C. Spousal violence in sub-Saharan Africa : does household poverty-wealth matter? Reprod Health. 2014;11:45.

75. Abeya SG, Afework MF, Yalew AW. Intimate partner violence against women in West Ethiopia: a qualitative study on attitudes, woman's response, and suggested measures as perceived by community members. Reprod Health. 2012;9:14.

76. Bazargan-Hejazi S, Medeiros S, Mohammadi R, Lin J, Dalal K. Patterns of intimate partner violence: a study of female victims in Malawi. J Inj Violence Res. 2013:5(1):38-50.

77. Zacarias AE, Macassa G, Svanström L, Soares JJF, Antai D. Intimate partner violence against women in Maputo city, Mozambique. BMC Int Health Hum Rights. 2012;12:35

78. Meekers D, Pallin SC, Hutchinson P. Intimate partner violence and mental health in Bolivia. BMC Womens Health. 2013;13:28.

79. Abeya SG, Afework MF, Yalew AW. Intimate partner violence against women in western Ethiopia: prevalence, patterns, and associated factors. BMC Public Health. 2011;11:913

80. Wandera SO, Kwagala B, Ndugga P, Kabagenyi A. Partners' controlling behaviors and intimate partner sexual violence among married women in Uganda. BMC Public Health. 2015;15:214.

81. Deyessa N, Berhane Y, Alem A, Ellsberg M, Emmelin M, Hogberg U, et al Clinical Practice and Epidemiology Intimate partner violence and depression among women in rural Ethiopia: a cross-sectional study. BMC Clin Pract Epidemiol Ment Heal. 2009;5:8.

82. Valladares $E$, Pen $R$, Persso LA, Högberg U. Violence against pregnant women : prevalence and characteristics. A population-based study in Nicaragua. BJOG Int J Obstet Gynaecol. 2005;112:1243-8.

83. Abramsky T, Devries K, Kiss L, Nakuti J, Kyegombe N, Starmann E, et al. Findings from the SASA ! Study : a cluster randomized controlled trial to assess the impact of a community mobilization intervention to prevent violence against women and reduce HIV risk in Kampala, Uganda. BMC Med. 2014;12:122.

84. Gupta J, Falb KL, Lehmann H, Kpebo D, Xuan Z, Hossain M, et al. Gender norms and economic empowerment intervention to reduce intimate partner violence against women in rural Côte d ' Ivoire: a randomized controlled pilot study. BMC Int Health Hum Rights. 2013;13:46.

85. Pulerwitz J, Hughes L, Mehta M, Kidanu A, Verani F, Tewolde S. Changing gender norms and reducing intimate partner violence: results from a quasiexperimental intervention Study with young men in Ethiopia. Am J Public Heal. 2015;105:132-7.

86. Falb KL, Annan J, Kpebo D, Cole H, Willie T, Luan Z, et al. Differential impacts of an intimate partner violence prevention program based on child marriage status in rural Côte d'Ivoire. J Adolesc Health. 2015;57:553-8.

87. Krishnan S, Vohra D, De WD, Medlin C, Nathan R, Dow WH. Tanzanian Couples' Perspectives on Gender Equity, Relationship Power, and Intimate Partner Violence: Findings from the RESPECT Study. Hindawi Publ Corp AIDS Res Treat. 2012;2012:187890.

88. Wagman JA, Gray RH, Campbell JC, Thoma M, Ssekasanvu J, Nalugoda F, et al. Effectiveness of an integrated intimate partner violence and HIV prevention intervention in Rakai, Uganda: analysis of an intervention in an existing cluster randomised cohort. HHS public access. Lancet Glob Heal. 2015;3(1):e23-33.

89. Green EP, Blattman C, Jamison J, Annan J. Women's entrepreneurship and intimate partner violence: a cluster randomized trial of microenterprise assistance and partner participation in post-conflict Uganda. Soc Sci Med. 2015;133:177-88.

90. Abramsky T, Devries KM, Michau L, Nakuti J, Musuya T, Kiss L, et al. Ecological pathways to prevention: how does the SASA ! Community mobilisation model work to prevent physical intimate partner violence against women? BMC Public Health. 2016;16:339. https://doi.org/10.1186/ s12889-016-3018-9.

91. Borenstein M, Hedges L, Higgins J, Rothstein H. Comprehensive Meta analysis (CMA) version 2.0; 2004.

92. Higgins JPT, Thompson SG. Quantifying heterogeneity in a meta-analysis. Stat Med. 2002;1558:1539-58.

93. Higgins JPT, Altman DG, Gøtzsche PC, Jüni P, Moher D, Oxman AD. The Cochrane collaboration ' $s$ tool for assessing risk of bias in randomised trials. BMJ. 2011;343:d5928.

94. Egger M, Smith GD, Schneider M, Minder C. Bias in meta-analysis detected by a simple, graphical test. BMJ. 1997;315:629-34.

95. Shi X, Nie C, Shi S, Wang T, Yang H, Zhou Y. Effect comparison between Egger's test and Begg's test in publication Bias diagnosis in Meta-analyses: evidence from a pilot survey. Int J Res Stud Biosci. 2017;5(5):14-20.

96. DerSimonian R, Laird N. Meta-analysis in clinical trials revisited: HHS public access. Contemp Clin Trials. 2015:45(0 0):139-45.

97. Heise LL. Violence against women: an integrated, ecological framework. Violence Against Women. 1998:4(3):262-90.

98. García-moreno C, Zimmerman C, Morris-gehring A, Heise L, Amin A, Abrahams $\mathrm{N}$, et al. Violence against women and girls 5 addressing violence against women : a call to action. Lancet. 2015;385:1685-95.

99. Garcia-moreno C, Jansen HAFM, Ellsberg M, Heise L, Watts CH, Study WHOM. Prevalence of intimate partner violence: findings from the $\mathrm{WHO}$ multi-country study on women's health and domestic violence. Lancet. 2006;368:1260-9.

100. Jewkes R. Intimate partner violence: causes and prevention; violence against women III. Lancet. 2002;359:1423-9.

101. Michau L, Horn J, Bank A, Dutt M, Zimmerman C. Violence against women and girls prevention of violence against women and girls: lessons from practice. Lancet. 2015;385:1672-84.

102. Jewkes $R$, Flood M, Lang J. Violence against women and girls: from work with men and boys to changes of social norms and reduction of inequities in gender relations: a conceptual shift in prevention of violence against women and girls. Lancet. 2015;385:1580-9. 